\title{
1 AGL16 negatively modulates stress response to balance with growth
}

2 Ping-Xia Zhao, Jing Zhang, Si-Yan Chen, Jie Wu, Jing-Qiu Xia, Liang-Qi Sun,

3 Shi-Song Ma and Cheng-Bin Xiang

4

5 School of Life Sciences and Division of Molecular \& Cell Biophysics, Hefei National

6 Science Center for Physical Sciences at the Microscale, University of Science and

7 Technology of China, The Innovation Academy of Seed Design, Chinese Academy of

8 Sciences, Hefei, Anhui Province 230027, China.

9

10 Corresponding author:

11 Cheng-Bin Xiang

12 School of Life Sciences

13 University of Science and Technology of China

14 Hefei, Anhui 230027

15 China.

Phone: 551-63600429

17 Email: xiangcb@ustc.edu.cn 


\section{ABSTRACT}

Sensile plants constantly experience environmental stresses in nature. They must have evolved effective mechanisms to balance growth with stress response. Here we report the MADS-box transcription factor AGL16 acting as a negative regulator in stress response. Loss-of- $A G L 16$ confers resistance to salt stress in seed germination, root elongation, and soil-grown plants, while elevated AGL16 expression confers the opposite phenotypes compared with wild type. However, the sensitivity to ABA in seed germination is inversely correlated with AGL16 expression level. Transcriptomic comparison revealed that the improved salt resistance of agll6 mutant was largely attributed to enhanced expression of stress responsive transcriptional factors and genes involved in ABA signaling and ion homeostasis. We further demonstrated that AGL16 directly binds to the CArG motifs in the promoter of $H K T 1 ; 1, H s f A 6 a$, and MYB102 and represses their expression. Genetic analyses with double mutants also support that HsfA6a and MYB102 are target genes of AGL16. Taken together, our results show that AGL16 acts as negative regulator transcriptionally suppressing key components in stress response and may play a critical role in balancing stress response with growth.

Key words: AGL16, salt resistance, MADS-box, seed germination, primary root elongation, ABA signaling 


\section{INTRODUCTION}

Plants suffer abiotic stresses in their life cycle. Soil salinity is a major abiotic stress that induces osmotic and oxidative stress and disturbs cellular ion and redox homeostasis, resulting in a substantial decrease of crop productivity worldwide (Miller et al., 2010; Schroeder et al., 2013; Golldack et al., 2014).

Plants have evolved a sophisticated network to cope with unfavorable environmental stresses. When exposed to salt stress, plants have effective responses to sense both hyperosmotic change and ionic fluctuation to deal with these stresses (Deinlein et al., 2014). But little is known about how salt stress is sensed by plants. Potential candidate of $\mathrm{Na}^{+}$sensors for salinity stress sensing in plants were predicted, including SOS1 $\mathrm{Na}^{+} / \mathrm{H}^{+}$antiporters, histidine kinase AtHK1, cation- $\mathrm{H}^{+}$exchangers, $\mathrm{NCX} \mathrm{Na}{ }^{+} / \mathrm{Ca}^{2+}$ exchangers, NSCC/NADPH oxidase, mechanosensory channels and transporters, cyclic nucleotide receptors, purino-receptors, annexins, and $\mathrm{H}^{+}$-ATPase/GORK tandem (Urao et al., 1999; Zhu, 2003; Kurusu et al., 2013; Maathuis, 2014; Shabala et al., 2015; Wu, 2018; Duszyn et al., 2019). For hyperosmotic sense, it may be closely coupled with $\mathrm{Ca}^{2+}$ channels as demonstrated by rapidly increased $\mathrm{Ca}^{2+}$ levels in cytosolic with $\mathrm{NaCl}$ or mannitol treatment (Knight et al., 1997; Kurusu et al., 2013; Yuan et al., 2014; Manishankar et al., 2018). To date, Arabidopsis reduced hyperosmolality-induced $\left[\mathrm{Ca}^{2+}\right]_{\mathrm{i}}$ increase 1 (OSCA1) functions as an osmosensor in plants, which was involved in osmotic stress induced fast signaling response by formed a hyperosmolality-gated calcium-permeable channel (Yuan et al., 2014). Recently, plant cell-surface GIPC sphingolipids was reported to sense salt to trigger $\mathrm{Ca}^{2+}$ influx (Jiang et al., 2019). Salt stress-induced long-distance $\mathrm{Ca}^{2+}$ waves rapidly participate in stress response in plants, which is devoted to whole-plant stress tolerance by depending on the activity of the ion channel protein Two Pore Channel 1 (TPC1) (Choi et al., 2014).

$\mathrm{Na}^{+}$and $\mathrm{Cl}^{-}$accumulate to high levels under salt stress, leading to physiological disorders in plants. Therefore, sustaining low $\mathrm{Na}^{+}$level and $\mathrm{Na}^{+}$exclusion in shoots are pivotal for decreasing the damage of glycophytes in salt-affected soil (Deinlein et 
al., 2014; Munns and Gilliham, 2015). The Salt-Overly Sensitive (SOS) pathway including SOS1, SOS2, and SOS3 and transporting $\mathrm{Na}^{+}$across the plasma membrane has been well characterized (Zhu, 2002, 2016; Yang and Guo, 2018). The key plasma membrane $\mathrm{Na}^{+} / \mathrm{H}^{+}$antiporter SOS 1 transports $\mathrm{Na}^{+}$in the root back into the soil solution, thus reducing $\mathrm{Na}^{+}$load from the xylem sap, which somehow triggers a cytoplasmic $\mathrm{Ca}^{2+}$ signal (Qiu et al., 2002; Pardo et al., 2006; Zhu, 2016).

Tonoplast-localized $\mathrm{Na}^{+} / \mathrm{H}^{+}$exchanger, $\mathrm{NHX} 1$ compartmentalized $\mathrm{Na}^{+}$into the vacuole to avoid the cytosolic accumulation of toxic $\mathrm{Na}^{+}$(Blumwald et al., 2000). Overexpression of $\mathrm{NHX1}$ increases salt tolerance in Arabidopsis transgenic plants (Apse et al., 1999). Moreover, NHX1 and NHX2 are essential for active $\mathrm{K}^{+}$uptake at the tonoplast, $\mathrm{pH}$ regulation in vacuole, and turgor generation for cell expansion (Leidi et al., 2010; Bassil et al., 2011; Barragan et al., 2012).

Efficient $\mathrm{Na}^{+}$retrieval from the xylem stream to the surrounding tissues is important to reduce the accumulation of $\mathrm{Na}^{+}$in shoots. High-affinity $\mathrm{K}^{+}$transporter (HKT) family members are involved in $\mathrm{Na}^{+}$-selective transport and $\mathrm{Na}^{+}$accumulation in shoots by mediating xylem $\mathrm{Na}^{+}$unloading as shown in several plant species (Maser et al., 2002; Ren et al., 2005; Sunarpi et al., 2005; Horie et al., 2009). Arabidopsis $H K T 1 ; 1$ functions in $\mathrm{Na}^{+}$retrieval from the xylem and $\mathrm{K}^{+}$homeostasis in shoots during salinity stress (Maser et al., 2002; Sunarpi et al., 2005; Davenport et al., 2007). The Arabidopsis $h k t 1 ; 1$ mutant is hypersensitive to salt stress due to over accumulation of $\mathrm{Na}^{+}$in shoots (Maser et al., 2002; Berthomieu et al., 2003), while enhanced expression of $H K T 1 ; 1$ decreased $\mathrm{Na}^{+}$level in shoots under salt stress (Moller et al., 2009). HKT1 also positively contributes to natural selection of saline adaptive Arabidopsis thaliana accessions (An et al., 2017).

Hormone signals play crucial roles in transcriptional regulation in response to salinity (Geng et al., 2013). Salt stress causes rapid and dynamic changes in the expression of stress responsive genes in plants, which overlaps with the response to abscisic acid (ABA) (Fujita et al., 2011; Geng et al., 2013). Primary root and lateral root growth show divergent temporal dynamics during salt stress, in which ABA and GA signaling crosstalks (Duan et al., 2013). 
Transcription factors (TF) are key components modulating stress adaptive pathways in plant stress responses. Core members of TFs, including basic leucine zipper (bZIP), MYB, MYC, (ERF)/APETALA2 (AP2), basic helix-loop-helix (bHLH), NAC, and WRKY family, are differentially expressed in response to exogenous salinity (Golldack et al., 2011; Deinlein et al., 2014). TFs mediate abiotic stress tolerance mostly by regulating stress-specific genes involved in ion homeostasis or osmotic adjustment.

MADS-box family members are known for their roles in the regulation of flowering development (Messenguy and Dubois, 2003; Pinyopich et al., 2003; Lee and Lee, 2010; Callens et al., 2018). Some members of this TF family function in seed germination and root development. For example, ANR1 regulates lateral root growth in response to change in the external $\mathrm{NO}_{3}{ }^{-}$supply, affects primary root development (Zhang and Forde, 1998; Gan et al., 2005; Gan et al., 2012), and acts as a modulator synergistically with AGL21 to regulate the expression of $A B I 3$ in seed germination (Lin et al., 2019). XAL1/AGL12 acts as an important regulator of cell proliferation in the root (Rounsley et al., 1995; Tapia-Lopez et al., 2008; Garcia-Cruz et al., 2016). Furthermore, XAL2/AGL14 modulates auxin transport during Arabidopsis primary root development by regulating PIN1 and PIN4 expression (Garay-Arroyo et al., 2013; Alvarez-Buylla et al., 2019). Moreover, AGL21, a member of the ANR1 clade, positively regulates auxin accumulation in lateral root primordia and lateral root initiation and growth (Yu et al., 2014b).

In this work, we continue to dissect the molecular mechanisms of EDT1/HDG11-conferred stress resistance by focusing on the down-regulated AGL16 in edt1 mutant. Our study shows that AGL16 is responsive to salt, osmotic stress, and $\mathrm{ABA}$ at the transcription level. Loss-of-function mutants agll6-2 and agll6 are more resistant to salt stress in seed germination and primary root elongation than the wild type, and more sensitive to ABA, indicating that AGL16 plays an important role in regulating salt tolerance in Arabidopsis. Transcriptomic analyses show that AGL16 negatively regulates the expression of stress responsive genes. We further demonstrated that AGL16 represses the transcription of HKT1;1, HsfA6a, and 
MYB102 by directly binding to their promoters, suggesting that $H K T 1 ; 1, H s f A 6 a$ and MYB102 are target genes of AGL16, which is consistent with the genetic analyses of double mutants. Together, our study revealed that AGL16 acts as an important negative regulator in stress response and may participate in the balance between growth and stress response.

\section{RESULTS}

\section{AGL16 negatively regulates seed germination in response to abiotic stress}

To investigate the role of $A G L 16$ in stress response, we obtained a T-DNA insertion line that we named agl16, the CRISPR/Cas9-edited AGL16 knockout mutant agl16-2, and generated AGL16 overexpression lines (OX) as described (Zhao et al., 2020), then seed germination assays were conducted. The seeds of wild type (Col-0), agl16-2, agl16, OX-17, OX-24 lines were germinated on MS medium with or without salt, mannitol, or ABA, and germination $\%$ was checked every day for 7 days. On MS medium, the seed germination rates showed no obvious difference among the genotypes. However, on medium with salt or mannitol, agll6-2 and agll6 mutants seed germination were less sensitive compared with the wild type, while OX lines were more sensitive to the treatments. In response to ABA treatment, agll6-2 and agll6 mutants displayed a reduced germination rate compared with the wild type, while OX lines showed more resistant germination to ABA inhibition than Col-0 (Figure 1A-B). Additionally, green cotyledon percentages of these genotypes displayed similar responses to the treatments as their seed germination did (Figure 1C). These results indicate that AGL16 negatively regulates seed germination in response to abiotic stress.

\section{AGL16 negatively regulates primary root elongation in response to abiotic stress}

To confirm the role of AGL16 in stress response, we further conducted primary root elongation assays. The seeds of Col-0, agll6-2, agll6, OX-17, OX-24 lines were germinated on MS medium for 4 days, and then transferred to MS medium with or 
159 without salt, mannitol or ABA and vertically grew for another 8 days. Primary root 160 length was measured at the indicated time points. Under normal growth conditions 161 (MS), no difference was found in primary root length among Col-0, agl16-2, agl16, OX-17, OX-24 lines. When subjected to salt and mannitol treatment, agll6-2 and agl16 mutants showed a less sensitive primary root elongation, while the overexpression lines displayed a considerable reduction compared to Col-0 (Figure 2A-B). Similarly, the fresh weight of agll6-2 and agll6 mutants were significantly higher than that of Col-0 after salt and mannitol treatment, while OX lines exhibited lower fresh weight (Figure 2C). In response to ABA treatment, agll6-2 and agll6 mutant were more sensitive in primary root elongation, while the OX lines were much less sensitive compared to Col-0 (Figure 2A-B). Similarly, fresh weight was significantly decreased in agll6-2 and agll6 mutant compared with that of Col-0, while OX lines exhibited the opposite (Figure 2A-C).

To explore whether cell division was affected by AGL16, we crossed the agl16-2, agl16 mutant or OX lines with CyclinB1;1-GUS reporter, respectively to examine the mitotic activity in the root meristems. Under normal conditions, GUS signals were similar in the root meristem between the wild type, agll6-2, agll6 mutant, and OX lines. In the salt and mannitol stressed roots, the activity of cell division was stronger in agll6-2 and agll6 mutants but significantly decreased in root meristem of OX lines compare with that of Col-0 (Figure 3). When treated with ABA, GUS signals were attenuated in agll6-2 and agll6 mutants compared to Col-0, while enhanced in the OX lines. Thus, mitotic activity in root meristem is one contributor to the AGL16-mediated primary root elongation in response to abiotic stress.

To evaluate the function of AGL16 in stress response of rosette stage plants, we performed salt tolerance assay on plants grown in soil. Soil-grown plants did not exhibit any apparent difference among Col-0, agl16-2, agl16, and OX lines under normal growth conditions. When 3-week old, soil-grown plants were watered with $250 \mathrm{mM} \mathrm{NaCl}$ solution and grown for 15 days before survival \% was recorded. The loss-of-function mutants agll6-2, agll6 lines exhibited a higher survival than Col-0, 
while OX-17 line showed the lowest survival (Figure 4A-B).

Next, we analyzed $\mathrm{Na}^{+}$and $\mathrm{K}^{+}$content in shoots and roots of Col-0, agll6, OX seedlings exposed to moderate salt stress. Under non-stress conditions, the content of $\mathrm{Na}^{+}, \mathrm{K}^{+}$were similar in shoots and roots of Col-0, agl16, OX lines (Figure 4C-F). Under salt stress, less $\mathrm{Na}^{+}$was accumulated in the shoots of agll6 mutant than that of Col-0, while OX lines had significantly higher $\mathrm{Na}^{+}$levels. However, in the roots, no significant difference in $\mathrm{Na}^{+}$content was seen between Col-0 and agll6 but the OX root had a higher level than Col-0 (Figure 4D, F). Under the same salt stress, shoot $\mathrm{K}^{+}$ levels did not differ between OX and Col-0 lines, but agll6 mutant had lower $\mathrm{K}^{+}$ compared with that of Col-0 (Figure 4C). In contrast, root $\mathrm{K}^{+}$level in agll6 mutant was significantly higher than that of Col-0, while the OX had a similar $\mathrm{K}^{+}$level as the wild type (Figure 4C, E). These results suggest that AGL16 may influence $\mathrm{Na}^{+}$and $\mathrm{K}^{+}$ content and therefore ion homeostasis in roots and shoots, leading to altered salt resistance seen in agll6 and OX lines.

\section{$A G L 16$ responds to multiple stresses and AGL16 protein always localizes in the nucleus.}

We previously showed higher expression levels of AGL16 in leaves, stem, and siliques by quantitative RT-PCR analyses (Zhao et al., 2020). To learn a more detailed tissue expression pattern, we generated AGL16pro-GUS transgenic plants and examined that the transcript abundance of $A G L 16$ in different tissues by GUS staining under normal conditions (Figure S1A). AGL16 was primarily expressed in radicle of germinating seeds ( Figure S1Aa-b). In 5-day-, 10-day-, 15-day- and 20-day-old plants, GUS staining was found in both leaves and roots (Figure S1Ac-f) where it was mainly located in root tip and stele ( Figure S1Ag-h). In maturing plants, AGL16 was mainly expressed in rosette leaves, cauline leaves, flowers, and siliques (Figure S1Ai-k).

To further study the response of $A G L 16$ expression to abiotic stress during root development, we examined the transcript level of AGL16 by qRT-PCR in 7-day-old wild type (Col-0) seedlings treated with salt, mannitol, and ABA for 0, 0.5, 1, 2, 3, 6, 12, 24 hours. Under normal condition, the transcript levels of AGL16 did not show 
significant difference. However, the expression of AGL16 was down regulated after salt, mannitol treatment for 24 hours, and gradually upregulated by ABA treatment and peaked at 3 hours after the treatment (Figure S1B). We also observed the responses in AGL16pro-GUS transgenic plants to salt, mannitol, ABA treatment. GUS signals in root tip and stele gradually declined by salt and mannitol treatment. However, to ABA treatment, GUS signal peaked at 3 hours after the treatment and declined in root tip and stele (Figure S1C). The GUS staining results are largely consistent with the qRT-PCR results (Figure S1B).

Moreover, AGL16 responds to multiple exogenous signals, such as root development (Figure S1D).

To localize AGL16 protein in the cell, we generated 35S:AGL16-GFP transgenic plants and found that the subcellular localization of AGL16 protein was in the nucleus of 7-day-old seedling roots by confocal laser scanning microscope (Figure S1E).

\section{The response of $A G L 16$ to $\mathrm{ABA}$ is directly mediated by $\mathrm{ABA}$ signaling and} biosynthesis pathway in modulating seed germination

Since loss-of-function mutants agl16-2, agll6 were hypersensitive to exogenous ABA in seed germination, we next investigated the role of AGL16 in imbibed seeds in response to ABA. qRT-PCR analyses showed that the transcript level of AGL16 was strongly elevated by exogenous ABA in wild-type (Col-0) seeds after 2-3 days imbibition (Figure 5A). We further tested whether AGL16 is involved in the regulation of ABA signaling by examining AGL16 transcript level in ABA insensitive (abi) mutants in the absence or presence of exogenous ABA. As shown in Figure 5B, AGL16 expression was significantly induced by ABA treatment only in Col-0, abi4-1, and abi5-7 mutants. However, the induced expression of AGL16 was abolished in abi1-1, abi2-2, abi3-8 mutants. Meanwhile, the agl16 abi5 double mutant exhibited alleviated ABA hypersensitivity (Figure 4C-E). These data suggest that AGL16 acts downstream of $\mathrm{ABI} 1, \mathrm{ABI} 2$ and $\mathrm{ABI} 3$ in $\mathrm{ABA}$ signaling to regulate seed germination. signaling, including $A B I 1, A B I 2, S n R K 2.2$, SnRK2.3, $A B I 3, A B I 4, A B I 5$, and related to 
downstream ABA responsive genes, such as $E M 1, E M 6, R A B 18, R D 29 B$. qRT-PCR results showed that $A B I 4, A B I 5, E M 6, R A B 18, R D 29 B$ were upregulated in agl16 mutant and downregulated in OX line compare to Col-0 in repsonse to exogenously applied ABA (Figure S2F-H, J-K), suggesting that AGL16 is a key node in ABA-response signaling pathway during seed germination. In addition, the expression level of ABA biosynthesis-related genes $A B A 2, N C E D 3, A A O 3$ was also upregulated in agll6 mutant compared with that of Col-0 after ABA treatment (Figure S2M, O-P). Whereas, the expression of key ABA catabolic enzyme family genes CYP707A1-CYP707A4 have no significant difference (Figure S2Q-T). Taken together, these results suggest that AGL16-modulated seed germination involves ABA signaling and biosynthesis.

\section{Enhanced transcript levels of salt stress-responsive genes in agl16 mutant}

To understand how AGL16 regulates salt tolerance in Arabidopsis, we measured the expression levels of salt stress-related genes in the wild type, agl16, and OX seedlings in response to salt stress with qRT-PCR. The transcript levels of $R D 29 A$, $R D 29 B, R A B 18, R D 22$, and $C B F 4$ were significantly upregulated in agl16 mutant compared with those in Col-0 plants (Figure S3A-E). The expression levels of SOS1, SOS2, NHX1, which are salt-inducible genes involved in ion homeostasis, were also altered in agl16 mutant but not significantly changed compared with wild type (Figure S3F-H). In contrast, transcript level of HKTl;1 was markedly elevated in agll6 mutant but reduced in OX line (Figure S3I), suggesting that AGL16 may directly repress the expression of $H K T 1 ; 1$ considering the AGL16 expression pattern in root stele and leaf vasculature (Figure $\mathrm{S} 1 \mathrm{Ah}$ ) which is similar to $\mathrm{Na}^{+}$transporter $\mathrm{HKT1;1}$ (Maser et al., 2002).

\section{RNA-seq analyses reveal global AGL16-regulated genes}

To explore the regulatory network of AGL16-mediated stress response in plant growth, we performed RNA-seq analysis to identify differentially expressed genes (DEGs) (> 1.5 fold change, $\mathrm{p}<0.05$ ) between 7-day-old Col-0, agl16, and OX-17 seedlings exposed to salt treatment for 0, 3 hours. Figure S4A-D shows that the most of genes were concentrated, only a few of genes were scattered, indicating expression 
of these genes was strongly regulated by AGL16. Comparative analysis of the DEGs between agl16 mutant, OX and Col-0 revealed that the number of DEGs was increased in (KO vs WT)-salt and (OX vs WT)-salt groups, suggesting that AGL16 influences the transcript profile in response to salt stress (Figure 5A). Furthermore, a small fraction of genes were differentially expressed between agl16, OX line, and Col-0 by comparison of DEGs number among (KO vs WT)-control, (OX vs WT)-control and (KO vs WT)-salt, (OX vs WT)-salt groups (Figure 5B). These co-regulated genes in agl16, OX and Col-0 line may be the candidate targets of AGL16.

In order to gain further insight into the regulatory network of AGL16 in response to short-term salt stress, a gene ontology (GO) analysis was performed for significantly up-regulated and down-regulated genes in (KO vs WT)-control, (OX vs WT)-control, (KO vs WT)-salt, and (OX vs WT)-salt pair-wise groups based on the biological process. Many DEGs from the (KO vs WT)-control group involved in pathways of response to heat, wounding, salt stress, jasmonic acid were highly enriched (Figure S5A). Several categories, including microtubule movement, response to wounding, jasmonic acid, heat, have preferential enrichment in (OX vs WT)-control group (Figure S5B). When treated with salt, numerous genes from the (KO vs WT)-salt group were assigned to abiotic stress-related terms, including response to water deprivation, salt stress, abscisic acid, and osmotic stress (Figure S5C). DEGs were significantly enriched for terms including glucosinolate biosynthesis, response to water deprivation, oxidation-reduction process, and DNA replication in (OX vs WT)-salt group (Figure S6D). GO analyses showed that salt-regulated genes were involved in AGL16-mediated abiotic tolerance.

Furthermore, the hierarchical clustering was conducted to analysis the expression profile of DEGs in response to salt stress. As shown in Figure 5C, the transcript levels of well-known abiotic stress- or ABA-responsive genes, such as NCED3, RAB18, $K I N 1, C O R 15 B, D R E B 2 A, A B I 5, A B F 3$ were significantly higher in the KO vs WT (salt stressed) group. Moreover, the expression level of salt stress-responsive transcription factors, including NAC055, NAC019, MYB102, HsfA6a, ZAT6 were also 
higher in agl16 mutant. Besides, AGL16 also affected the expression of a number of genes related to ion transport (Table S1).

Thus, we selected a few DEGs known to mediate abiotic stress response to verify their transcript levels in Col-0, agl16, OX-17 line. The transcript level of HsfA6a and MYB102 were upregulated in agl16 mutant and downregulated in OX line compared with the Col-0 under salt treatment for 3, 12 hours (Figure S6). However, the expression level of $b Z I P 1, N H X 2$ were not downregulated in OX compared with the Col-0 at 3, 12 hours. Therefore, we hypothesized AGL16 may directly regulate the expression of HsfA6a and MYB102, two known TFs in stress resistance (Denekamp and Smeekens, 2003; Hwang et al., 2014).

AGL16 directly regulates $H K T 1 ; 1, H s f A 6 a$ and $M Y B 102$ in salt stress response

To determine whether AGL16 interacts directly with the promoter of $H K T 1 ; 1$, $H s f A 6 a$ and MYB102 or represses their expression indirectly, we found three putative AGL16-binding sites (CC-A/T-rich-GG or C-A/T-rich-G) in each $2.0 \mathrm{~kb}$ promoter region of $H K T 1 ; 1, H s f A 6 a, M Y B 102$ (Figure 7-9A). We constructed transgenic Arabidopsis plants that overexpressed HA-AGL16 fusion protein, and performed chromatin immunoprecipitation (ChIP) assays. The promoter fragments (about $200 \mathrm{bp}$ ) with cis1 site of $H K T 1 ; 1$, cis1 and cis3 sites of $H s f A 6 a$, and cis2 site of MYB102 were markedly enriched in 35S:HA-AGL16 transgenic plants by PCR and qRT-PCR (Figure 7-9B-C). To test the ability of AGL16 as a transcription repressor, we constructed the effector that the coding sequence of $A G L 16$ was driven by the cauliflower mosaic virus (CaMV) 35S promoter, and reporters that a $2000 \mathrm{bp}$ promoter or $26 \mathrm{bp}$ promoter fragments contained CArG motifs of $H K T 1 ; 1, H s f A 6 a$ and $M Y B 102$ were respectively fused to the luciferase (LUC) reporter gene. When effector and reporter were both transfected into Arabidopsis protoplasts, AGL16 was able to suppress the expression of the $H K T 1 ; 1, H s f A 6 a$ and $M Y B 102$ promoter-driven luciferase (LUC) reporter gene (Figure 7-9D), demonstrating that AGL16 can directly regulate the expression of HKT1;1, HsfA6a and MYB102 in vivo. Moreover, we performed yeast-one-hybrid $(\mathrm{Y} 1 \mathrm{H})$ and EMSA assays to confirm the specific binding. $\mathrm{Y} 1 \mathrm{H}$ results displayed that AGL16 can interact with cis1 site of $H K T 1 ; 1$ promoter, cis1 and cis3 sites of $H s f A 6 a$ 
promoter, and cis2 site of MYB102 promoter (Figure 7-9C). EMAS assays also demonstrated that AGL16 binds specifically to the cis element (Figure 7-9E). The above results suggest that AGL16 represses the expression of $H K T 1 ; 1, H s f A 6 a$ and MYB102 by directly binding to the CArG motifs in their promoters in vivo and in vitro.

\section{HsfA6 a and MYB102 acts downstream of AGL16}

35S:HsfA6a overexpression lines are insensitive to salt and drought, but sensitive to ABA (Hwang et al., 2014). To further verify the genetic interaction between AGL16 and $H s f A 6 a, M Y B 102$ in modulating seeds germination and primary root elongation in response to abiotic stress, we crossed agl16 mutant with the hsfa6a, myb102 mutants respectively and obtained the double mutants agll6 hsfa6a and agll6 myb102. The genetic analyses showed that seed germination rate and green cotyledon rate were similar in Col-0, agll6, hsfa6a, agl16 hsfa6a lines on MS medium (Figure 10A-C), but agll6 hsfa6a double mutant was more resistant to mannitol and $\mathrm{NaCl}$ in seed germination and post germination, but more sensitive to ABA than $h s f a 6 a$ mutant (Figure 10A-C). As expected, the primary roots length of the agll6 hsfa6a double mutant was longer than those of hsfa6a mutant when subjected to salt and mannitol stress, while more inhibited than hsfa6a mutant by ABA treatment (Figure 10D-E).

The agl16 myb102 double mutant displayed an increased germination rate and green cotyledon rate compared with myb102 mutant when subjected to mannitol and $\mathrm{NaCl}$ stress, while more sensitive to $\mathrm{ABA}$ in germination (Figure 11A-C). The primary root elongation displayed similar trends as seed germination in agll6 myblo2 mutant in response to mannitol, $\mathrm{NaCl}$ and $\mathrm{ABA}$ treatment (Figure 11D-E).

Taken together, these data support that HsfA6a and MYB102 act downstream of $A G L 16$, consistent with our biochemical and mocelcular evidence as the direct targets of AGL16.

\section{DISCUSSION}




\section{AGL16 acts as an important negative regulator in stress response}

In Arabidopsis, the MADS-box proteins play an important regulatory role in shoot development, but their roles in response to environmental stresses are still not well characterized (Yu et al., 2014a; Alvarez-Buylla et al., 2019). Previously, we reported that MADS-box TF AGL16 acts as a negative regulator in drought resistance by modulating leaf stomatal density and stomatal movement (Zhao et al., 2020). In the present study, we further demonstrated that AGL16 is also involved in ABA-mediated seed germination and seedling growth in response to salt and osmotic stress. The transcript abundance of AGL16 decreased in response to $\mathrm{NaCl}$ and mannitol stress while increased under ABA treatment (Figure S1B-C), indicating that AGL16 is involved in the response to multiple abiotic stresses. We found that agl16-2 and agll6 knockout mutants were less sensitive to $\mathrm{NaCl}$ and mannitol treatments during seed germination and primary root elongation but hypersensitive to ABA treatment compared with wild type. In addition, the soil-grown mutant plants exhibit enhanced the salt tolerance, while the overexpression lines show the opposite phenotypes (Figure 1-4). Together, these results clearly show that AGL16 negatively regulates plant reponse to salt stress.

\section{$A G L 16$ is regulated by $\mathrm{ABA}$ signaling and responds to multiple stress and}

\section{hormone signals}

AGL16 belongs to the AGL17-like clade which includes ANR1, AGL21, and AGL17 members, having the overlapping expression pattern in MIKC-type group (Alvarez-Buylla et al., 2000; Burgeff et al., 2001). ANR1 and AGL21 both act as negative modulators of seed germination and by controlling the expression of $A B I 3$ or ABI5 respectively (Yu et al., 2017; Lin et al., 2019). In ABA signaling pathway, ABI3, $\mathrm{ABI} 4$, and $\mathrm{ABI} 5$ act as positive regulators that are necessary for achieving growth arrest when subjected to unfavorable conditions (Giraudat et al., 1992; Finkelstein and Lynch, 2000; Yamaguchi-Shinozaki and Shinozaki, 2006). ABI5 inhibits seed germination partly through activating the expression of LATE EMBRYOGENESIS ABUNDANT genes EM1 and EM6 (Finkelstein and Lynch, 2000; Carles et al., 2002; Lopez-Molina et al., 2002). 
Here we found that $A G L 16$ expression was significantly repressed in abil-1, abi2-2, abi3-8 mutants under ABA treatment (Figure 5B). ABI4, ABI5, EM6, RAB18, $R D 29 B$ were upregulated in agl16 mutant (Figure S2), suggesting that AGL16 is involved in ABA signaling pathway and likely acts downstream of $A B I 1, A B I 2$, and $A B I 3$, but upstream or in parallel with $A B I 4$ and $A B I 5$. Upon ABA treatment, the transcript levels of $A B A 3, A A O 3$, and $N C E D 3$ were upregulated to modulate the level of ABA in Arabidopsis (Chan, 2012; Vishal and Kumar, 2018). In agll6 mutant, the expression level of $A B A 2, N C E D 3, A A O 3$ was elevated ( Figure S2M, O-P), likely contributing to the hypersensitivity to exogenous ABA in agll6 mutant. Several TFs, such as ABR1, RGL2, WRKY2, WRKY41 were reported to regulate seed germination depending not only on ABA signaling pathway, but also on $\mathrm{ABA}$ biosynthesis (Pandey et al., 2005; Piskurewicz et al., 2008; Jiang and Yu, 2009; Ding et al., 2014).

Besides, a few studies reported that salt stress induces expression of genes related to auxin biosynthesis and transport, such as nitrilase 1 (NIT1) and PIN2 (Bao and Li, 2002; Sun et al., 2008). Ethylene and auxin have been shown to regulate growth and development processes, including primary root elongation (Swarup et al., 2007). In this study, $A G L 16$ responds to multiple stresses and hormones ethylene and IAA (Figure S1D) and affects cell division (Figure 3), suggesting that AGL16 may serve as a node integrating phytohormone signals derived from environmental stresses to mediate the adaptive response of primary root development.

\section{AGL16 enhances salinity tolerance by modulating ion homeostasis}

High salinity can cause hyperosmotic stress and sodium $\left(\mathrm{Na}^{+}\right)$toxicity in plants. Maintaining $\mathrm{Na}^{+}$and $\mathrm{K}^{+}$homeostasis in the cytosol by inhibition of $\mathrm{Na}^{+}$influx and promotion of $\mathrm{K}^{+}$uptake is critical for plant survival in salt tolerance (Yokoi et al., 2002; Sunarpi et al., 2005; Ma et al., 2011). Lower levels of $\mathrm{Na}^{+}$were accumulated in the shoots of agll6 mutant compared with Col-0 when exposed to $\mathrm{NaCl}$ (Figure 4D), while no significant difference was observed in roots (Figure 4F), indicating $\mathrm{Na}^{+}$level was decreased in shoots by increasing $\mathrm{Na}^{+}$influx into roots mostly via enhanced the expression of $H K T 1 ; 1$. AtHKT1;1 is expressed mainly in the root xylem parenchyma 
cells and plays an essential role in $\mathrm{Na}^{+}$exclusion from leaves and $\mathrm{K}^{+}$homeostasis in leaves under salinity stress (Maser et al., 2002; Horie et al., 2008). AGL16 was highly expressed in the stele (Figure S1Ah), which overlaps with HKT1;1 expression in the root, supporting that AGL16 regulates HKT1;1 expression. It has been reported that ABI4, represses $H K T 1 ; 1$ expression in the root stele and alters $\mathrm{Na}^{+}$unloading from xylem vessels to xylem parenchyma cells, increasing salt tolerance in abi4 mutants (Shkolnik-Inbar et al., 2013). Salt stress-induced bZIP24 regulates plant salt tolerance by directly or indirectly repressing the expression of HKT1;1 (Yang et al., 2009). AtNHX1 was not significantly affected by AGL16 in response to salt stress (Figure S3). Therefore, The loss-of-AGL16 improves salinity tolerance by enhancing the capacity of $\mathrm{Na}^{+}$extrusion rather than $\mathrm{Na}^{+}$sequestration.

\section{AGL16 negatively regulates a large array of stress-responsive genes}

Comparative transcriptomic analyses revealed that many DEGs involved in the response to heat, wounding, and jasmonic acid were found preferentially enriched in $\mathrm{KO}$ and OX lines under normal condition (Figure S5A-B), indicating that AGL16 may play an important role in the response to abiotic stresses and hormone signals. A number of genes related to water deprivation, salt stress, abscisic acid, osmotic stress were significantly enriched in KO vs WT (salt stressed) group (Figure S5C), indicating that the enhanced salt tolerance of agll6 may be attributed to increased ion and osmotic signaling, which activates the expression of downsteam stress-responsive genes, for instance, the stress- or ABA-responsive genes showed in Figure 5C, which are known to participate in abiotic stress response and improve plant resistance to multiple stresses when overexpressed (Nakashima et al., 2000; Zhu, 2002; Bartels and Sunkar, 2005).

TFs are major regulators of gene expression and also involved in the crosstalk between plant hormones and stress signaling (Fujita et al., 2006; Ku et al., 2018; Xie et al., 2019). Several stress-responsive TF genes were enriched in our RNA-seq data (Figure 6C), including HsfA6a and MYB102. HsfA6a (Hwang et al., 2014) and MYB102 (Denekamp and Smeekens, 2003) are known to be induced by abiotic stress or ABA. AtHsfA6a is highly induced by exogenous $\mathrm{ABA}, \mathrm{NaCl}$, and drought. The 
overexpression lines of $H s f A 6 a$ are hypersensitive to ABA and exhibit enhanced tolerance against salt and drought stress (Hwang et al., 2014).

MYB proteins are notable for their roles in regulation of multiple responses to hormone signaling, biotic and abiotic stresses (Dubos et al., 2010; Roy, 2016). MYB102 is expressed in almost all organs and rapidly induced by osmotic stress and ABA (Denekamp and Smeekens, 2003; Zhu et al., 2018), overlapping with the expression profiles of $A G L 16$, which suggests that it may play an important role in abiotic stress resistance. Indeed, loss-of-MYB102 significantly impairs the resistance to salt and osmotic stress in germination and root elongation (Figure 11).

Our genetic and biochemical analyses demonstrate that AGL16 acts upstream of HsfA6a and MYB102 and AGL16 suppresses the transcription of HsfA6a and MYB102 by directly binding to their promoter (Figure 8-11).

\section{AGL16 acts as a negative regulator of stress responses to balance between growth and stress response}

Sensile plants live in a constantly fluctuating environment. They must equipped with highly efficient and effective mechanisms to balance between growth and response to stresses. Plants maximize growth under favorable conditions, while under environmental stresses, they allocate resources to cope with stresses and slow down or stop growth. This dynamic switch must be finely tuned to ensure plant success in nature. In this study, we have characterized the MADS-box TF AGL16 as an important negative regulator that keeps stress response off or down when environmental stresses are absent or low. AGL16 regulates plant stress tolerance by transcriptionally suppressing a large array of stress responsive target genes including $H K T 1 ; 1, H s f A 6 a$, and MYB102 to maintain ion homeostasis and proper response to stress. Furthermore, AGL16 may mediates ABA signaling by negatively regulating ABI5 and ABA content. Therefore, our study suggests that AGL16 serves as an important modulator balancing between plant response to stress and plant growth, and provide a beneficial candidate for improving crop stress resistance. 


\section{METHODS}

\section{Plant materials and growth conditions.}

The wild type used in our study was Arabidopsis thaliana ecotype Columbia-0 (Col-0). All mutants and transgenic plants used in our work are in the Col-0 background. A homozygous AGL16 loss-function mutant agl16 (Salk_104701) was ordered from Arabidopsis Biological Resource Center (ABRC). The CRISPR/Cas9-edited AGL16 knockout mutant agl16-2, 35S:AGL16, 35S:HA-AGL16, AGL16pro: GUS, 35S:AGL16-GFP transgenic plants were obtained by transforming into Col-0 via Agrobacterium (C58C1) transformation using the Arabidopsis floral-dip method (Clough and Bent, 1998). agl16 CyclinB1:1, agl16-2 CyclinB1:1, 35S:AGL16 CyclinB1:1, agl16 hsfa6a and agl16 myb102 lines were obtained by genetic crossing separately.

Arabidopsis seeds were surface sterilized with $10 \%$ bleach for 15-20 minutes, and then washed four times at least with distilled water. Seeds were vernalized at $4{ }^{\circ} \mathrm{C}$ for 2 days in darkness, and then horizontally or vertically germinated on MS (Murashige and Skoog) medium with $1 \%(\mathrm{w} / \mathrm{v})$ sucrose at $22{ }^{\circ} \mathrm{C}, 60-80 \%$ relative humidity under 16-h light/8-h dark cycles. For seed germination assay, seeds were horizontally germinated on MS mediums with or without $120 \mathrm{mM} \mathrm{NaCl}, 250 \mathrm{mM}$ Mannitol, and 0.5 $\mu \mathrm{M}$ ABA for 7 days, germination (emergence of radicles) and post-germination growth (green cotyledon appearance) were scored at the indicated time points. For analysis of PR length, 4-day-old seedlings were transferred to MS mediums with or without $120 \mathrm{mM} \mathrm{NaCl}, 250 \mathrm{mM}$ Mannitol, and $5 \mu \mathrm{M}$ ABA for 8 days and grown vertically, the PR length of seedlings and fresh weights were measured at the indicated time points.

\section{Analysis of GUS activity}

The transgenic lines AGL16pro:GUS were obtained by the $2.5 \mathrm{~kb}$ promoter of AGL16 was cloned into pCB308R vector (Lei et al., 2007). The different tissues of seedlings and adult seedlings of AGL16pro: GUS transgenic plants were stained as described previously (Jefferson et al., 1987). GUS staining solution was prepared as 
described before (Cai et al., 2014). The GUS activities of individual parts were observed using a light microscope with a camera (HiROX).

\section{Subcellular localization}

The AGL16-coding region was constructed into pGWB5 vector (Nakagawa et al., 2007) and obtained transgenic plants by Agrobacterium (C58C1) transformation using the Arabidopsis floral-dip method. The green fluorescence of 35S:AGL16-GFP transgenic root tissues were observed under a ZEISS880 confocal laser scanning microscope with an excitation of $488 \mathrm{~nm}$ and an emission of $525 \mathrm{~nm}$ condition.

\section{RT-PCR and qRT-PCR analysis}

Total RNA of different tissues as indicated using TRIzol reagent (Invitrogen, Carlsbad, USA). RNA reverse reaction was carried out using Prime Script RT reagent kit (Takara, Dalian, China). The reverse reaction products were used as templates for RT-PCR amplification and qRT-PCR analysis. Applied Biosystem StepOne real-time PCR system and SYBR Premix Ex Taq II kit (Takara, Dalian, China) were used for the qRT-PCR detection. The transcript levels of different genes were normalized to that of UBIQUITIN5 (UBQ5) in qRT-PCR analysis.

\section{RNA-seq analysis}

For RNA-seq analysis, the Arabidopsis roots from 7-day-old Col-0, agll6, and OX-17 seedlings exposed to medium with salt treatment for 0,3 hours were respectively collected, then RNA was isolated using RNAprep Pure Plant Kit (TIANGEN, Beijing, China). The total RNA integrity was evaluated by Bioanalyzer 2100 (Agilent, California, USA) (RIN $\geq 7,28 \mathrm{~S} / 18 \mathrm{~S} \geq 1.5$ ), and RNA-seq library was sequenced by Beijing Biomarker Technology Company. In RNA-seq data, differentially expressed genes (DEGs) were characterized by the threshold (the absolute value of $\log _{2}$ (fold change) $\geq 1.5$, FDR $\leqslant 0.05$ ). GO term enrichment analysis for each differentially expressed genes was conducted by David tools (https://david.ncifcrf.gov/).

\section{ChIP assay}

7-day-old 35S:HA-AGL16 transgenic seedlings and Col-0 plants were used for ChIP assay. The procedure was conducted as described previously (Cai et al., 2014). 
547 The purified DNA fragments were used as templates for PCR amplification and 548 qRT-PCR detection with the same primers. For PCR analysis, PCR products were 549 detected by $2 \%$ agarose gel electrophoresis. The DNA binding ratio was calculated by qRT-PCR (Mukhopadhyay et al., 2008). $\beta$-tubulin8 was used as a negative control.

\section{Transient expression assay}

Transient expression assay was carried out as described previously (Wang et al., 2016). The AGL16-coding region was constructed into pGreenII 62-SK to generate an effector, and about 2000 bp promoter of HKT1;1, HsfA6a, MYB102 or putative $26 \mathrm{bp}$ fragment containing CArG motifs from these target genes promoter were respectively fused to pGreenII 0800-LUC to generate reporters (Hellens et al., 2005). The effector and reporter were subsequently transfected into Arabidopsis mesophyll protoplasts from 4-week-old wild-type (Col-0) leaves in short light as described (Yoo et al., 2007). The firefly LUC and REN activities luciferase were detected by transient dual-luciferase reporter assay system (Promega, Madison, USA), and LUC/REN ratio was calculated. The REN activity was used as an internal control.

\section{Yeast one-hybrid assay}

Yeast one-hybrid assay was conducted as described previously (Mao et al., 2016). The AGL16-coding region was constructed into pAD-GAL4-2.1 (pAD) and the putative 26 bp fragment containing CArG motifs from HKT1; 1, HsfA6a, MYB102 promoter were respectively cloned into pHIS2 (pBD) (Mu et al., 2009). These constructs of pAD and pHIS2 plasmids were introduced into Y187 yeast strain and grown on SD/-Trp-Leu medium with or without His plus $20 \mathrm{mM} 3$-aminotriazole and diluted as indicated $(1: 1,1: 10,1: 100,1: 1000)$.

\section{Electrophoretic mobility shift assay}

Electrophoretic mobility shift assay (EMSA) was performed as described previously (Miao et al., 2018). The AGL16-coding region was cloned into pET28a vector and His-AGL16 fusion protein was expressed in E. coli Rosseta2 strain. 30 bp free probes containing CArG motifs, non-competitor probes (mutated) were synthesized with biotinlabeled at the 5' end by a commercial company (Sangon Biotech, Shanghai, China), while competitor probes did not. Complementary ssDNA 
577 probes were mixed, $95^{\circ} \mathrm{C}$ for 10 min and slowly cooled down to $25^{\circ} \mathrm{C}$. EMSA was 578 performed using a LightShift ${ }^{\mathrm{TM}}$ EMSA Optimization and Control Kit (Thermo Fisher

579 Scientific, Waltham, USA). For competition assays, different concentrations of 580 competitor and non-competitor probes were added into the reaction system. Each 581 reaction was loaded on a $6 \%$ native polyacrylamide gel in $0.5 \times$ TBE buffer to 582 electrophoresis. The results were detected using a CCD camera system (Image Quant 583 LAS 4000).

\section{Genetic analysis}

The agl16 loss-of-function mutant was a female parent, abi5, hsfa6a or myb102 loss-of-function mutant was as male parent. They were crossed by transferring mature anthers of male parent to stigmas of female parent and obtained the homozygotes of double mutants.

\section{Statistical analysis}

Statistical analysis was conducted using one-way ANOVA. Values are the mean \pm SD and $\mathrm{P}<0.05$ was considered statistically significant. Different letters indicate a significant difference.

\section{Accession numbers}

Sequence data from this study can be found in the GenBank/EMBL libraries under the following accession numbers: AGL16 (AT3g57230), UBQ5 (AT3g62250), ABA1 (AT5g67030), ABA2 (AT1g52340), ABA3 (AT1g16540), NCED3 (AT3g14440), AAO3 (AT2g27150), CYP707A1 (AT4g19230), CYP707A2 (AT2g29090), CYP707A3 (AT5g45340), CYP707A4 (AT3g19270), ABII (AT4g26080), ABI2 (AT5g57050), SnRK2.2 (At3g50500), SnRK2.3 (At5g66880), ABI3 (AT3g24650), ABI4 (AT2g40220), ABI5 (AT2g36270), EM1 (AT3g51810), EM6 (AT2g40170), RAB18 (AT5g66400), RD29B (At5g52300), RD22 (At5g25610), RD29A (AT5g52310), CBF4 (AT5g51990), SOS1 (AT2g01980), SOS2 (AT5g35410), NHX1 (AT5g27150), HKT1;1 (AT4g10310), HsfA6a (At5g43840), MYB102 (At4g21440), COR15B (AT2g42530), NAC055 (AT3g15500), bZIP1 (AT5g49450), RAV1 (AT1g13260), NHX2 (AT3g05030), HAK5 (AT4g13420), RAP2.6 (AT1g43160), MYC5 (AT5g46830), RAS1 (AT1g09950). 
608 Supplemental information

609 Figure S1. Expression pattern of AGL16 and response to abiotic stresses during root

610 development.

611 Figure S2. The expression levels of ABA signaling, biosynthesis and catabolic-related 612 genes in Col-0, agll6, and OX-17 lines.

613 Figure S3. Expression profiles of salt stress-responsive genes in Col-0, agl16, OX 614 lines.

615 Figure S4. The distribution of differentially expressed genes (DEGs) in KO vs 616 WT-control, OX vs WT-control, KO vs WT-salt, and OX vs WT-salt groups.

617 Figure S5. GO term enrichment analysis of genes affected by AGL16.

618 Figure S6. The transcript levels of stress-responsive genes of RNA-Seq microarray 619 analysis.

620 Table S1. List of overlapped genes related to salt stress between KO vs WT-control, 621 OX vs WT-control, KO vs WT-salt, and OX vs WT-salt groups.

622 Table S2. Primers used in this study.

623

624

\section{ACKNOWLEDGEMENTS}

625

626

627

628

629

630

631

632

633

634

This study was supported by grants from National Natural Science Foundation of China (31900230 to P.Z.), China Postdoctoral Science Foundation (2020T130634 and 2019M652200 to P.Z.) and Youth Innovation Foundation of University of Science and Technology of China (WK2070000186). We thank the ABRC for providing the mutant seeds.

\section{AUTHOR CONTRIBUTIONS}

P.Z. and C.X. designed the experiments. P.Z., J.Z., Y.C., J.W., J.X., L.S., S.M. performed the experiments and data analyses. P.Z. wrote the manuscript. C.X supervised the project and revised the manuscript. 
bioRxiv preprint doi: https://doi.org/10.1101/2021.02.16.431464; this version posted February 17, 2021. The copyright holder for this preprint (which was not certified by peer review) is the author/funder. All rights reserved. No reuse allowed without permission.

635 


\section{REFERENCE}

637

638

639

640

641

642

643

644

645

646

647

648

649

650

651

652

653

654

655

656

657

658

659

660

661

662

663

664

665

666

667

668

669

670

671

672

673

674

675

676

677

678

Alvarez-Buylla, E.R., Garcia-Ponce, B., Sanchez, M.P., Espinosa-Soto, C., Garcia-Gomez, M.L., Pineyro-Nelson, A., and Garay-Arroyo, A. (2019). MADS-box genes underground becoming mainstream: plant root developmental mechanisms. New Phytol.

Alvarez-Buylla, E.R., Liljegren, S.J., Pelaz, S., Gold, S.E., Burgeff, C., Ditta, G.S., Vergara-Silva, F., and Yanofsky, M.F. (2000). MADS-box gene evolution beyond flowers: expression in pollen, endosperm, guard cells, roots and trichomes. Plant J 24, 457-466.

An, D., Chen, J.G., Gao, Y.Q., Li, X., Chao, Z.F., Chen, Z.R., Li, Q.Q., Han, M.L., Wang, Y.L., Wang, Y.F., and Chao, D.Y. (2017). AtHKT1 drives adaptation of Arabidopsis thaliana to salinity by reducing floral sodium content. PLoS Genet 13, e1007086.

Apse, M.P., Aharon, G.S., Snedden, W.A., and Blumwald, E. (1999). Salt tolerance conferred by overexpression of a vacuolar $\mathrm{Na}^{+} / \mathrm{H}^{+}$antiport in Arabidopsis. Science 285, 1256-1258.

Bao, F., and Li, J.Y. (2002). Evidence That the Auxin Signaling Pathway Interacts with Plant Stress Response. Acta Botanica Sinica 44, 532-536.

Barragan, V., Leidi, E.O., Andres, Z., Rubio, L., De Luca, A., Fernandez, J.A., Cubero, B., and Pardo, J.M. (2012). Ion exchangers NHX1 and NHX2 mediate active potassium uptake into vacuoles to regulate cell turgor and stomatal function in Arabidopsis. The Plant cell 24, 1127-1142.

Bartels, D., and Sunkar, R. (2005). Drought and salt tolerance in plants. Crit Rev Plant Sci 24, 23-58.

Bassil, E., Tajima, H., Liang, Y.C., Ohto, M.A., Ushijima, K., Nakano, R., Esumi, T., Coku, A., Belmonte, M., and Blumwald, E. (2011). The Arabidopsis $\mathrm{Na}^{+} / \mathrm{H}^{+}$antiporters NHX1 and NHX2 control vacuolar $\mathrm{pH}$ and $\mathrm{K}^{+}$homeostasis to regulate growth, flower development, and reproduction. The Plant cell 23, 3482-3497.

Berthomieu, P., Conejero, G., Nublat, A., Brackenbury, W.J., Lambert, C., Savio, C., Uozumi, N., Oiki, S., Yamada, K., Cellier, F., Gosti, F., Simonneau, T., Essah, P.A., Tester, M., Very, A.A., Sentenac, H., and Casse, F. (2003). Functional analysis of AtHKT1 in Arabidopsis shows that $\mathrm{Na}^{+}$recirculation by the phloem is crucial for salt tolerance. EMBO J 22, 2004-2014.

Blumwald, E., Aharaon, G.S., and Apse, M.P. (2000). Sodium transport in plant cells. BBA Rev 1465, 140-151.

Burgeff, C., Liljegren, S.J., Tapia-López, R., Yanofsky, M.F., and Alvarez-Buylla, E.R. (2001). MADS-box gene expression in lateral primordia, meristems and differentiated tissues of Arabidopsis thaliana roots. Planta 214, 365-372.

Cai, X.T., Xu, P., Zhao, P.X., Liu, R., Yu, L.H., and Xiang, C.B. (2014). Arabidopsis ERF109 mediates cross-talk between jasmonic acid and auxin biosynthesis during lateral root formation. Nat Commun 5, 5833.

Callens, C., Tucker, M.R., Zhang, D., and Wilson, Z.A. (2018). Dissecting the role of MADS-box genes in monocot floral development and diversity. J Exp Bot 69, 2435-2459.

Carles, C., Bies-Etheve, N.A., L., Leon-Kloosterziel, K.M., Koornneef, M.E., M. , and Delseny, M. (2002). Regulation of Arabidopsis thaliana Em genes: role of ABI5. Plant J 30, 373-383.

Chan, Z. (2012). Expression profiling of ABA pathway transcripts indicates crosstalk between abiotic and biotic stress responses in Arabidopsis. Genomics 100, 110-115.

Choi, W.G., Toyota, M., Kim, S.H., Hilleary, R., and Gilroy, S. (2014). Salt stress-induced Ca ${ }^{2+}$ waves are associated with rapid, long-distance root-to-shoot signaling in plants. Proc Natl Acad Sci U S A 
111, 6497-6502.

Clough, S.J., and Bent, A.F. (1998). Floral dip: a simplified method for Agrobacterium-mediated transformation of Arabidopsis thaliana. Plant J 16, 735-743.

Davenport, R.J., Munoz-Mayor, A., Jha, D., Essah, P.A., Rus, A., and Tester, M. (2007). The $\mathrm{Na}^{+}$ transporter AtHKT1;1 controls retrieval of $\mathrm{Na}^{+}$from the xylem in Arabidopsis. Plant Cell Environ 30, 497-507.

Deinlein, U., Stephan, A.B., Horie, T., Luo, W., Xu, G., and Schroeder, J.I. (2014). Plant salt-tolerance mechanisms. Trends Plant Sci 19, 371-379.

Denekamp, M., and Smeekens, S.C. (2003). Integration of wounding and osmotic stress signals determines the expression of the AtMYB102 transcription factor gene. Plant Physiol 132, 1415-1423.

Ding, Z.J., Yan, J.Y., Li, G.X., Wu, Z.C., Zhang, S.Q., and Zheng, S.J. (2014). WRKY41 controls Arabidopsis seed dormancy via direct regulation of $A B I 3$ transcript levels not downstream of ABA. Plant J 79, 810-823.

Duan, L., Dietrich, D., Ng, C.H., Chan, P.M., Bhalerao, R., Bennett, M.J., and Dinneny, J.R. (2013). Endodermal ABA signaling promotes lateral root quiescence during salt stress in Arabidopsis seedlings. The Plant cell 25, 324-341.

Dubos, C., Stracke, R., Grotewold, E., Weisshaar, B., Martin, C., and Lepiniec, L. (2010). MYB transcription factors in Arabidopsis. Trends Plant Sci 15, 573-581.

Duszyn, M., Swiezawska, B., Szmidt-Jaworska, A., and Jaworski, K. (2019). Cyclic nucleotide gated channels (CNGCs) in plant signalling-Current knowledge and perspectives. J Plant Physiol 241, 153035.

Finkelstein, R.R., and Lynch, T.J. (2000). The Arabidopsis abscisic acid response gene $A B I 5$ encodes a basic leucine zipper transcription factor. The Plant cell 12, 599-609.

Fujita, M., Fujita, Y., Noutoshi, Y., Takahashi, F., Narusaka, Y., Yamaguchi-Shinozaki, K., and Shinozaki, K. (2006). Crosstalk between abiotic and biotic stress responses: a current view from the points of convergence in the stress signaling networks. Curr Opin Plant Biol 9, 436-442.

Fujita, Y., Fujita, M., Shinozaki, K., and Yamaguchi-Shinozaki, K. (2011). ABA-mediated transcriptional regulation in response to osmotic stress in plants. J Plant Res 124, 509-525.

Gan, Y., Filleur, S., Rahman, A., Gotensparre, S., and Forde, B.G. (2005). Nutritional regulation of ANR1 and other root-expressed MADS-box genes in Arabidopsis thaliana. Planta 222, 730-742.

Gan, Y., Bernreiter, A., Filleur, S., Abram, B., and Forde, B.G. (2012). Overexpressing the ANR1 MADS-box gene in transgenic plants provides new insights into its role in the nitrate regulation of root development. Plant Cell Physiol 53, 1003-1016.

Garay-Arroyo, A., Ortiz-Moreno, E., de la Paz Sanchez, M., Murphy, A.S., Garcia-Ponce, B., Marsch-Martinez, N., de Folter, S., Corvera-Poire, A., Jaimes-Miranda, F., Pacheco-Escobedo, M.A., Dubrovsky, J.G., Pelaz, S., and Alvarez-Buylla, E.R. (2013). The MADS transcription factor XAL2/AGL14 modulates auxin transport during Arabidopsis root development by regulating PIN expression. EMBO J 32, 2884-2895.

Garcia-Cruz, K.V., Garcia-Ponce, B., Garay-Arroyo, A., Sanchez, M.P., Ugartechea-Chirino, Y., Desvoyes, B., Pacheco-Escobedo, M.A., Tapia-Lopez, R., Ransom-Rodriguez, I., Gutierrez, C., and Alvarez-Buylla, E.R. (2016). The MADS-box XAANTAL1 increases proliferation at the Arabidopsis root stem-cell niche and participates in transition to differentiation by regulating 
cell-cycle components. Ann Bot 118, 787-796.

Geng, Y., Wu, R., Wee, C.W., Xie, F., Wei, X., Chan, P.M.Y., Tham, C., Duan, L., and Dinneny, J.R. (2013). A spatio-temporal understanding of growth regulation during the salt stress response in Arabidopsis. The Plant cell 25, 2132-2154.

Giraudat, J., Hauge, B.M., Valon, C., Smalle, J., Parcy, F., and Goodman, H.M. (1992). Isolation of the Arabidopsis $A B / 3$ gene by positional cloning. The Plant cell 4.

Golldack, D., Luking, I., and Yang, O. (2011). Plant tolerance to drought and salinity: stress regulating transcription factors and their functional significance in the cellular transcriptional network. Plant cell reports 30, 1383-1391.

Golldack, D., Li, C., Mohan, H., and Probst, N. (2014). Tolerance to drought and salt stress in plants: Unraveling the signaling networks. Front Plant Sci 5, 151.

Hellens, R.P., Allan, A.C., Friel, E.N., Bolitho, K., Grafton, K., Templeton, M.D., Karunairetnam, S., Gleave, A.P., and Laing, W.A. (2005). Transient expression vectors for functional genomics, quantification of promoter activity and RNA silencing in plants. Plant Methods 1, 13.

Horie, T., Hauser, F., and Schroeder, J.I. (2009). HKT transporter-mediated salinity resistance mechanisms in Arabidopsis and monocot crop plants. Trends Plant Sci 14, 660-668.

Horie, T., Sugawara, M., Okunou, K., Nakayama, H., Schroeder, J.I., Shinmyo, A., and Yoshida, K. (2008). Functions of HKT transporters in sodium transport in roots and in protecting leaves from salinity stress. Plant Biotech 25, 233-239.

Hwang, S.M., Kim, D.W., Woo, M.S., Jeong, H.S., Son, Y.S., Akhter, S., Choi, G.J., and Bahk, J.D. (2014). Functional characterization of Arabidopsis HsfA6a as a heat-shock transcription factor under high salinity and dehydration conditions. Plant Cell Environ 37, 1202-1222.

Jefferson, R.A., Kavanagh, T.A., and Bevan, M.W. (1987). GUS fusions: beta-glucuronidase as a sensitive and versatile gene fusion marker in higher plants. EMBO J 6, 3901-3907.

Jiang, W., and Yu, D. (2009). Arabidopsis WRKY2 transcription factor mediates seed germination and postgermination arrest of development by abscisic acid. BMC Plant Biol 9, 96.

Jiang, Z., Zhou, X., Tao, M., Yuan, F., Liu, L., Wu, F., Wu, X., Xiang, Y., Niu, Y., Liu, F., Li, C., Ye, R., Byeon, B., Xue, Y., Zhao, H., Wang, H.N., Crawford, B.M., Johnson, D.M., Hu, C., Pei, C., Zhou, W., Swift, G.B., Zhang, H., Vo-Dinh, T., Hu, Z., Siedow, J.N., and Pei, Z.M. (2019). Plant cell-surface GIPC sphingolipids sense salt to trigger $\mathrm{Ca}(2+)$ influx. Nature 572, 341-346.

Knight, H., Trewavas, A.J., and Knight, M.R. (1997). Calcium signaling in Arabidopsis thaliana responding to drought and salinity. Plant J 12, 1067-1078.

Ku, Y.S., Sintaha, M., Cheung, M.Y., and Lam, H.M. (2018). Plant hormone signaling crosstalks between biotic and abiotic stress responses. Int J Mol Sci 19.

Kurusu, T., Kuchitsu, K., Nakano, M., Nakayama, Y., and lida, H. (2013). Plant mechanosensing and $\mathrm{Ca}^{2+}$ transport. Trends Plant Sci 18, 227-233.

Lee, J., and Lee, I. (2010). Regulation and function of SOC1, a flowering pathway integrator. J Exp Bot 61, 2247-2254.

Lei, Z.Y., Zhao, P., Cao, M.J., Cui, R., Chen, X., Xiong, L.Z., Zhang, Q.F., Oliver, D.J., and Xiang, C.B. (2007). High-throughput binary vectors for plant gene function analysis. J Integr Plant Biol 49, 556-567.

Leidi, E.O., Barragán, V., Rubio, L., El-Hamdaoui, A., Ruiz, M.T., Cubero, B., Fernández, J.A., Bressan, R.A., Hasegawa, P.M., Quintero, F.J., and Pardo, J.M. (2010). The AtNHX1 exchanger mediates potassium compartmentation in vacuoles of transgenic tomato. Plant J 61, 495-506. 
Lin, J.H., Yu, L.H., and Xiang, C.B. (2019). ARABIDOPSIS NITRATE REGULATED 1 acts as a negative modulator of seed germination by activating ABI3 expression. New Phytol 225, 835-847.

Lopez-Molina, L., Mongrand, S., McLachlin, D.T.C., B. T. , and Chua, N.H. (2002). ABI5 acts downstream of $A B \mid 3$ to execute an $A B A$-dependent growth arrest during germination. Plant J 32, 317-328.

Ma, L., Zhang, H., Sun, L., Jiao, Y., Zhang, G., Miao, C., and Hao, F. (2011). NADPH oxidase AtrbohD and AtrbohF function in ROS-dependent regulation of $\mathrm{Na}^{+} / \mathrm{K}^{+}$homeostasis in Arabidopsis under salt stress. J Exp Bot 63, 305-317.

Maathuis, F.J. (2014). Sodium in plants: perception, signalling, and regulation of sodium fluxes. J Exp Bot 65, 849-858.

Manishankar, P., Wang, N., Koster, P., Alatar, A.A., and Kudla, J. (2018). Calcium signaling during salt stress and in the regulation of ion homeostasis. J Exp Bot 69.

Mao, J.L., Miao, Z.Q., Wang, Z., Yu, L.H., Cai, X.T., and Xiang, C.B. (2016). Arabidopsis ERF1 mediates cross-talk between ethylene and auxin biosynthesis during primary root elongation by regulating ASA1 Expression. PLoS Genetics 12, e1005760.

Maser, P., Eckelman, B., Vaidyanathan, R., Horie, T., and Fairbairn, D.J. (2002). Altered shoot/root $\mathrm{Na}^{+}$ distribution and bifurcating salt sensitivity in Arabidopsis by genetic disruption of the $\mathrm{Na}^{+}$ transporter AtHKT1. FEBS Lett 531.

Messenguy, F., and Dubois, E. (2003). Role of MADS box proteins and their cofactors in combinatorial control of gene expression and cell development. Gene 316, 1-21.

Miao, Z.Q., Zhao, P.X., Mao, J.L., Yu, L.H., Yuan, Y., Tang, H., Liu, Z.B., and Xiang, C.B. (2018). HOMEOBOX PROTEIN52 mediates the crosstalk between ethylene and auxin signaling during primary root elongation by modulating auxin transport-related gene expression. The Plant cell 30, 2761-2778.

Miller, G., Suzuki, N., Ciftci-Yilmaz, S., and Mittler, R. (2010). Reactive oxygen species homeostasis and signalling during drought and salinity stresses. Plant Cell Environ 33, 453-467.

Moller, I.S., Gilliham, M., Jha, D., Mayo, G.M., Roy, S.J., Coates, J.C., Haseloff, J., and Tester, M. (2009). Shoot $\mathrm{Na}^{+}$exclusion and increased salinity tolerance engineered by cell type-specific alteration of $\mathrm{Na}^{+}$transport in Arabidopsis. The Plant cell 21, 2163-2178.

Mu, R.L., Cao, Y.R., Liu, Y.F., Lei, G., Zou, H.F., Liao, Y., Wang, H.W., Zhang, W.K., Ma, B., Du, J.Z., Yuan, M., Zhang, J.S., and Chen, S.Y. (2009). An R2R3-type transcription factor gene AtMYB59 regulates root growth and cell cycle progression in Arabidopsis. Cell Res 19, 1291-1304.

Mukhopadhyay, A., Deplancke, B., Walhout, A.J., and Tissenbaum, H.A. (2008). Chromatin immunoprecipitation (ChIP) coupled to detection by quantitative real-time PCR to study transcription factor binding to DNA in Caenorhabditis elegans. Nat Protoc 3, 698-709.

Munns, R., and Gilliham, M. (2015). Salinity tolerance of crops - what is the cost? New Phytol 208, 668-673.

Nakagawa, T., Kurose, T., Hino, T., Tanaka, K., Kawamukai, M., Niwa, Y., Toyooka, K., Matsuoka, K., Jinbo, T., and Kimura, T. (2007). Development of series of gateway binary vectors, pGWBs, for realizing efficient construction of fusion genes for plant transformation. J Biosci Bioeng 104, 34-41.

Nakashima, K., Shinwari, Z., K. , Sakuma, Y., Seki, M., Miura, S., Shinozaki, K., and Yamaguchi-Shinozaki, K. (2000). Organization and expression of two Arabidopsis DREB2 genes encoding DRE-binding proteins involved in dehydration- and high-salinity-responsive 
gene expression. Plant Mol Bio 42, 657-665.

Pandey, G.K., Grant, J.J., Cheong, Y.H., Kim, B.G., Li, L., and Luan, S. (2005). ABR1, an APETALA2-domain transcription factor that functions as a repressor of ABA response in Arabidopsis. Plant Physiol 139, 1185-1193.

Pardo, J.M., Cubero, B., Leidi, E.O., and Quintero, F.J. (2006). Alkali cation exchangers: roles in cellular homeostasis and stress tolerance. J Exp Bot 57, 1181-1199.

Pinyopich, A., Ditta, G.S., Savidge, B., Liljegren, S.J., Baumann, E., Wisman, E., and Yanofsky, M.F. (2003). Assessing the redundancy of MADS-box genes during carpel and ovule development. Nature 424, 85-88.

Piskurewicz, U., Jikumaru, Y., Kinoshita, N., Nambara, E., Kamiya, Y., and Lopez-Molina, L. (2008). The gibberellic acid signaling repressor RGL2 inhibits Arabidopsis seed germination by stimulating abscisic acid synthesis and ABI5 activity. The Plant cell 20, 2729-2745.

Qiu, Q.S., Guo, Y., Dietrich, M.A., Schumaker, K.S., and Zhu, J.K. (2002). Regulation of SOS1, a plasma membrane $\mathrm{Na}^{+} / \mathrm{H}^{+}$exchanger in Arabidopsis thaliana, by SOS2 and SOS3. P NATL ACAD SCI USA 99, 8436-8441.

Ren, Z.H., Gao, J.P., Li, L.G., Cai, X.L., Huang, W., Chao, D.Y., Zhu, M.Z., Wang, Z.Y., Luan, S., and Lin, H.X. (2005). A rice quantitative trait locus for salt tolerance encodes a sodium transporter. Nat Genet 37, 1141-1146.

Rounsley, S.D., Ditta, G.S., and Yanofsky, M.F. (1995). Diverse Roles for MADS Box Genes in Arabidopsis Development. Plant Cell 7, 1259-1269.

Roy, S. (2016). Function of MYB domain transcription factors in abiotic stress and epigenetic control of stress response in plant genome. Plant Signal Behav 11, e1117723.

Schroeder, J.I., Delhaize, E., Frommer, W.B., Guerinot, M.L., Harrison, M.J., Herrera-Estrella, L., Horie, T., Kochian, L.V., Munns, R., Nishizawa, N.K., Tsay, Y.F., and Sanders, D. (2013). Using membrane transporters to improve crops for sustainable food production. Nature 497, 60-66.

Shabala, S., Wu, H., and Bose, J. (2015). Salt stress sensing and early signalling events in plant roots: Current knowledge and hypothesis. Plant Sci 241, 109-119.

Shkolnik-Inbar, D., Adler, G., and Bar-Zvi, D. (2013). ABI4 downregulates expression of the sodium transporter HKT1;1 in Arabidopsis roots and affects salt tolerance. Plant J 73, 993-1005.

Sun, F., Zhang, W., Hu, H., Li, B., Wang, Y., Zhao, Y., Li, K., Liu, M., and Li, X. (2008). Salt modulates gravity signaling pathway to regulate growth direction of primary roots in Arabidopsis. Plant Physiol 146, 178-188.

Sunarpi, Horie, T., Motoda, J., Kubo, M., Yang, H., Yoda, K., Horie, R., Chan, W.Y., Leung, H.Y., Hattori, K., Konomi, M., Osumi, M., Yamagami, M., Schroeder, J.I., and Uozumi, N. (2005). Enhanced salt tolerance mediated by AtHKT1 transporter-induced $\mathrm{Na}^{+}$unloading from xylem vessels to xylem parenchyma cells. Plant J 44, 928-938.

Swarup, R., Perry, P., Hagenbeek, D., Van Der Straeten, D., Beemster, G.T., Sandberg, G., Bhalerao, R., Ljung, K., and Bennett, M.J. (2007). Ethylene upregulates auxin biosynthesis in Arabidopsis seedlings to enhance inhibition of root cell elongation. Plant Cell 19, 2186-2196.

Tapia-Lopez, R., Garcia-Ponce, B., Dubrovsky, J.G., Garay-Arroyo, A., Perez-Ruiz, R.V., Kim, S.H., Acevedo, F., Pelaz, S., and Alvarez-Buylla, E.R. (2008). An AGAMOUS-related MADS-box gene, XAL1 (AGL12), regulates root meristem cell proliferation and flowering transition in Arabidopsis. Plant Physiol 146, 1182-1192.

Urao, T., Yakubov, B., Satoh, R., Yamaguchi-Shinozaki, K., Seki, M., Hirayama, T., and Shinozaki, K. 
(1999). A transmembrane hybrid-type-histidine kinase in arabidopsis functions as an osmosensor. The Plant cell 11, 1743-1754.

Vishal, B., and Kumar, P.P. (2018). Regulation of seed germination and abiotic stresses by gibberellins and abscisic Aacid. Front Plant Sci 9, 838.

Wang, H., Pan, J., Li, Y., Lou, D., Hu, Y., and Yu, D. (2016). The DELLA-CONSTANS transcription factor cascade integrates gibberellic acid and photoperiod signaling to regulate flowering. Plant Physiol 172, 479-488.

Wu, H. (2018). Plant salt tolerance and $\mathrm{Na}^{+}$sensing and transport. Crop J 6, 215-225.

Xie, Z., Nolan, T.M., Jiang, H., and Yin, Y. (2019). AP2/ERF transcription factor regulatory networks in hormone and abiotic stress responses in Arabidopsis. Front Plant Sci 10, 228.

Yamaguchi-Shinozaki, K., and Shinozaki, K. (2006). Transcriptional regulatory networks in cellular responses and tolerance to dehydration and cold stresses. Annu Rev Plant Biol 57, 781-803.

Yang, O., Popova, O.V., Suthoff, U., Luking, I., Dietz, K.J., and Golldack, D. (2009). The Arabidopsis basic leucine zipper transcription factor AtbZIP24 regulates complex transcriptional networks involved in abiotic stress resistance. Gene 436, 45-55.

Yang, Y., and Guo, Y. (2018). Elucidating the molecular mechanisms mediating plant salt-stress responses. New Phytol 217, 523-539.

Yokoi, S., Quintero, F.J., Cubero, B., Ruiz, M.T., Bressan, R.A., Hasegawa, P.M., and Pardo, J.M. (2002). Differential expression and function of Arabidopsis thaliana $\mathrm{NHX} \mathrm{Na} / \mathrm{H}^{+}$antiporters in the salt stress response. Plant J 30.

Yoo, S.D., Cho, Y.H., and Sheen, J. (2007). Arabidopsis mesophyll protoplasts: a versatile cell system for transient gene expression analysis. Nat Protoc 2, 1565-1572.

Yu, C., Su, S., Xu, Y., Zhao, Y., Yan, A., Huang, L., Ali, I., and Gan, Y. (2014a). The effects of fluctuations in the nutrient supply on the expression of five members of the AGL17 clade of MADS-box genes in rice. PLoS One 9, e105597.

Yu, L.H., Miao, Z.Q., Qi, G.F., Wu, J., Cai, X.T., Mao, J.L., and Xiang, C.B. (2014b). MADS-box transcription factor $A G L 21$ regulates lateral root development and responds to multiple external and physiological signals. Mol Plant 7, 1653-1669.

Yu, L.H., Wu, J., Zhang, Z.S., Miao, Z.Q., Zhao, P.X., Wang, Z., and Xiang, C.B. (2017). Arabidopsis MADS-Box transcription factor AGL21 acts as environmental surveillance of seed germination by regulating ABI5 expression. Mol Plant 10, 834-845.

Yuan, F., Yang, H., Xue, Y., Kong, D., Ye, R., Li, C., Zhang, J., Theprungsirikul, L., Shrift, T., Krichilsky, B., Johnson, D.M., Swift, G.B., He, Y., Siedow, J.N., and Pei, Z.M. (2014). OSCA1 mediates osmotic-stress-evoked $\mathrm{Ca}^{2+}$ increases vital for osmosensing in Arabidopsis. Nature 514, 367-371.

Zhang, H.M., and Forde, B.G. (1998). An Arabidopsis MADS Box Gene That Controls Nutrient-Induced Changes in Root Architecture. Science 279, 407-409.

Zhao, P.-X., Miao, Z.-Q., Zhang, J., Chen, S.-Y., Liu, Q.-Q., and Xiang, C.-B. (2020). Arabidopsis MADS-box factor AGL16 negatively regulates drought resistance via stomatal density and stomatal movement. J Exp Bot.

Zhu, J.K. (2002). Salt and drought stress signal transduction in plants. Annu Rev Plant Biol 53, 247-273.

Zhu, J.K. (2003). Regulation of ion homeostasis under salt stress. Curr Opin Plant Biol 6, 441-445.

Zhu, J.K. (2016). Abiotic stress signaling and responses in plants. Cell 167, 313-324.

Zhu, L., Guo, J., Ma, Z., Wang, J., and Zhou, C. (2018). Arabidopsis transcription factor MYB102 
increases plant susceptibility to aphids by substantial activation of ethylene biosynthesis. Biomole 8.

901

902 
Figure 1. Response of $A G L 16$ to abiotic stress in seed germination

(A-C) Seed germination of Col-0, agl16-2, agl16, and AGL16 overexpression (OX)

Seed germination rate was measured at the indicated time points (B). Green cotyledon rate was measured every day for 7 days $(C)$. Values are mean \pm SD $(n=3$ replicates, 60 seeds/replicate). Different letters indicate significant difference by one-way ANOVA $(\mathrm{P}<0.05)$.

\section{Figure 2. Primary root elongation of agl16 mutants and AGL16 overexpression}

914

915

916 lines in response to abiotic stress.

(A-B) Primary root elongation. Seeds of Col-0, agl16-2, agll6, and OX lines were germinated on MS medium for 4 days respectively, then seedlings were transferred to MS medium with or without $120 \mathrm{mM} \mathrm{NaCl}, 250 \mathrm{mM}$ mannitol and $5 \mu \mathrm{M}$ ABA for 8 days. Photographs were taken (A) and primary root length was measured at the indicated time points (B). Values are the mean $\pm S D(n=3$ replicates, 30 seedlings/replicate). Different letters indicate significant difference by one-way ANOVA $(\mathrm{P}<0.05)$.

(C) The fresh weights. The fresh weights of 12-day-old seedlings of Col-0, agll6-2, agl16, and OX lines were measured. Values are mean $\pm \mathrm{SD}(\mathrm{n}=3$ replicates, 30 seedlings/replicate). Different letters indicate significant difference by one-way ANOVA $(\mathrm{P}<0.05)$.

Figure 3. CyclinB1;1 activity in primary root of Col-0, agl16-2, agl16, and AGL16 overexpression lines.

The CyclinB1;1-GUS maker was introduced in Col-0, agl16-2, agl16, and OX lines background by genetic crossing. The seeds were germinated on MS medium for 4 days, then seedlings were respectively transferred to MS medium with or without 120 $\mathrm{mM} \mathrm{NaCl}, 250 \mathrm{mM}$ mannitol, $5 \mu \mathrm{M}$ ABA and grown for 3 days before GUS staining. 
Seedlings $(>20)$ were incubated in GUS solution for 5 hours before photographs were taken. Bar $=100 \mu \mathrm{m}$.

Figure 4. AGL16 negatively modulates salt tolerance in Arabidopsis plants grown in soil.

(A-B) Salt tolerance assay in soil. 3-week old soil-grown seedlings of Col-0, agll6-2, agll6, and $\mathrm{OX}$ lines were irrigated with or without $250 \mathrm{mM} \mathrm{NaCl}$ for 2 weeks. Photographs were taken (A) and survival rate was calculated (B). Values are mean \pm $\mathrm{SD}(\mathrm{n}=3$ replicates, 60 seedlings/replicate). Different letters indicate significant difference by one-way ANOVA $(\mathrm{P}<0.05)$. (C-F) Ion accumulation in salt-treated Col-0, agl16, OX-17 plants. Seeds of Col-0, agl16, OX-17 lines were respectively germinated on MS medium for 4 days, then seedlings were transferred to MS medium with or without $120 \mathrm{mM} \mathrm{NaCl}$ and grown vertically for 10 days. Sodium, potassium content were quntified in shoots (C-D) and roots $(\mathrm{E}-\mathrm{F})$. Values are mean $\pm \mathrm{SD}(\mathrm{n}=3$ replicates, 50 seedlings/replicate). Different letters indicate significant difference by one-way ANOVA $(\mathrm{P}<0.05)$.

Figure 5. AGL16 expression is dependent on $\mathrm{ABA}$ signaling in seed germination. (A) The response of AGL16 expression to ABA in seeds. Vernalized wild type (Col-0) seeds were germinated on MS medium without (control) or with $0.5 \mu \mathrm{M} \mathrm{ABA}$ for 1,2 , 3 days. RNA was extracted from seeds and the transcript level of AGL16 was analyzed by qRT-PCR. Values are mean \pm SD ( $n=3$ replicates). Different letters indicate significant difference by one-way ANOVA $(\mathrm{P}<0.05)$.

(B) Transcript levels of AGL16 in abi mutants. Vernalized seeds of Col-0, abil-1, abi2-2, abi3-8, abi4-1, and abi5-7 were germinated on MS medium without (control) or with $0.5 \mu \mathrm{M}$ ABA for 24 hours, respectively. RNA was extracted and the transcript level of AGL16 was detected by qRT-PCR. Values are mean \pm SD ( $\mathrm{n}=3$ replicates). (C-E) AGL16 acts upstream of ABI5. Seeds of Col-0, agl16, abi5, agl16 abi5 lines were horizontally germinated on MS medium with or without $0.5 \mu \mathrm{M}$ ABA for 7 days. Photographs were taken (C). Seed germination rate (D) and green cotyledon rate were measured at 7 days after the end of stratification (E). Values are mean $\pm S D(n=3$ replicates, 60 seeds/ replicates). Different letters indicate significant difference by 
one-way ANOVA $(\mathrm{P}<0.05)$.

Figure 6. Transcriptomic analyses of differentially expressed genes (DEGs) affected by AGL16.

(A) The number of differentially expressed genes (DEGs). The statistics data of differentially expressed genes in (KO vs WT)-control, (OX vs WT)-control and (KO vs WT)-salt, (OX vs WT)-salt groups.

(B) Comparison of differentially expressed genes (DEGs) among (KO vs WT)-control, (OX vs WT)-control (KO vs WT)-salt, and (OX vs WT)-salt groups using Venn diagram. The numbers represent the total numbers of differentially expressed genes in different comparison groups.

(C) Hierarchical clustering analysis of salt stress-related genes affected by AGL16 in DEGs. The heatmap represents fold changes in the abundance of gene transcripts in different comparison groups.

\section{Figure 7. AGL16 binds to the CArG motif in the promoter of HKT1;1.}

(A) Schematic illustration of $H K T 1 ; 1$ promoter with AGL16 candidate CArG motifs. The number represents the location of CArG motifs in $H K T 1 ; 1$ promoter; Short lines of different colors mark the regions amplified in PCR and qRT-PCR analyses, while the black line represents the control region without CArG motifs.

(B) ChIP-PCR assay. 7-day-old 35S:HA-AGL16 transgenic plants and wild type (Col-0) were used for the ChIP-PCR assay. A region of HKT1; 1 that does not contain CArG motifs was used as a control. About 200 bp fragment cis 1 from HKT1;1 promoter containing the CArG motif was enriched by anti-HA antibodies as shown in PCR and qRT-PCR analyses. Values are mean \pm SD ( $n=3$ replicates). Different letters indicate significant difference by one-way ANOVA $(\mathrm{P}<0.05)$.

(C) Yeast one-hybrid assay. The coding sequence of AGL16 was constructed into pGADT7 (pAD) and the $26 \mathrm{bp}$ fragment containing the CArG motif of HKT1;1 promoter was cloned into pHIS2 (pBD). Different yeast culture dilutions (1:1, 1:10, 1:100, 1:1,000) were grown on SD/-Trp-Leu medium with or without His plus $20 \mathrm{mM}$ 3-AT. pAD/pBD, pAD-AGL16/pBD, pAD/pBD-cis1, pAD/pBD-cis2, pAD/pBD-cis3 were used as negative controls. 
(D) Transient transactivation assays. Schematic illustration of the effector and reporters used in the transient transactivation assays. AGL16 effector were under the control of the CaMV 35S promoter. HKT1;1 promoter and the 26 bp binding cis-element of $H K T 1 ; 1$ promoter were respectively fused to the LUC gene as reporters. The firefly LUC and REN activities luciferase were detected by transient dual-luciferase reporter assays, and LUC/REN ratio was calculated. The REN activity was used as an internal control. Values are mean \pm SD ( $n=3$ replicates). Different letters indicate significant difference by one-way ANOVA $(\mathrm{P}<0.05)$. (E) EMSA assay. The $26 \mathrm{bp}$ cis-element containing the CArG motif of HKT1;1 promoter was synthesized with biotin labelled at the $5^{\prime}$ end. Non-labelled probe was competitor. As indicated, AGL16-dependent mobility shifts were competed by the competitor probe in a dose-dependent manner.

(A) Schematic illustration of HsfA6a promoter with candidate CArG motifs. The number represents the location of CArG motifs in HsfA6a promoter; Short lines of different colors mark the regions amplified in PCR and qRT-PCR analyses, while the black line represents the control region without CArG motifs.

(B) ChIP-PCR assay. 7-day-old 35S:HA-AGL16 transgenic plants and wild type (Col-0) were used for the ChIP-PCR assay. A region of HsfA6a that does not contain CArG motifs was used as a control. About $200 \mathrm{bp}$ fragment cis 1 and cis 3 from HsfA6a promoter containing CArG motifs were enriched by anti-HA antibodies as shown in PCR and qRT-PCR analyses. Values are mean $\pm \mathrm{SD}(\mathrm{n}=3$ replicates). Different letters indicate significant difference by one-way ANOVA $(\mathrm{P}<0.05)$.

(C) Yeast one-hybrid assay. The coding sequence of AGL16 was constructed into pGADT7 (pAD) and the 26 bp fragment containing the CArG motif of HsfA6a promoter was cloned into pHIS2 (pBD). Different yeast culture dilutions (1:1, 1:10, 1:100, 1:1,000) were grown on SD/-Trp-Leu medium with or without His plus $20 \mathrm{mM}$ 3-AT. pAD/pBD, pAD-AGL16/pBD, pAD/pBD-cis1, pAD/pBD-cis2, pAD/pBD-cis3 were used as negative controls.

(D) Transient transactivation assays. Schematic illustration of the effector and 
reporters used in the transient transactivation assays. AGL16 effector were under the control of the CaMV 35S promoter. HsfA6a promoter and the 26 bp cis-elements of $H s f A 6 a$ promoter were respectively fused to the LUC gene as reporters. The firefly LUC and REN activities luciferase were detected by transient dual-luciferase reporter assays, and LUC/REN ratio was calculated. The REN activity was used as an internal control. Values are mean \pm SD $(n=3$ replicate). Different letters indicate significant difference by one-way ANOVA $(\mathrm{P}<0.05)$.

(E) EMSA assay. The 26 bp cis-element containing CArG motif of HsfA6a promoter were synthesized with biotin labelled at the 5' end. Non-labelled probe was used as competitor. As indicated, AGL16-dependent mobility shifts were competed by the competitor probe in a dose-dependent manner.

Figure 9. AGL16 binds to the CArG motifs in the promoter of MYB102.

(A) Schematic illustration of MYB102 promoter with AGL16 candidate CArG motifs. The number represents the location of CArG motifs in MYB102 promoter; Short lines of different colors mark the regions amplified in PCR and qRT-PCR analyses, while the black line represents the control region without CArG motifs.

(B) ChIP-PCR assay. 7-day-old 35S:HA-AGL16 transgenic plants and wild type (Col-0) were used for the ChIP-PCR assay. A region of MYB102 that does not contain CArG motifs was used as a control. About 200 bp fragment cis2 from MYB102 promoter containing CArG motifs was enriched by anti-HA antibodies as shown in PCR and qRT-PCR analyses. Values are mean \pm SD ( $n=3$ replicates). Different letters indicate significant difference by one-way ANOVA $(\mathrm{P}<0.05)$.

(C) Yeast one-hybrid assay. The coding sequence of AGL16 was constructed into pGADT7 (pAD) and the 26 bp fragment containing CArG motif of MYB102 promoter was cloned into pHIS2 (pBD). Different yeast culture dilutions $(1: 1,1: 10,1: 100$, 1:1,000) were grown on SD/-Trp-Leu medium with or without His plus 20 mM 3-AT. pAD/pBD, pAD-AGL16/pBD, pAD/pBD-cis1, pAD/pBD-cis2, pAD/pBD-cis3 were used as negative controls.

(D) Transient transactivation assays. Schematic illustration of the effector and reporters used in the transient transactivation assays. AGL16 effector were under the 
control of the CaMV 35S promoter. MYB102 promoter and the 26 bp cis-element of MYB102 promoter were respectively fused to the LUC gene as reporters. The firefly LUC and REN activities luciferase were detected by transient dual-luciferase reporter assays, and LUC/REN ratio was calculated. The REN activity was used as an internal control. Values are mean \pm SD ( $n=3$ replicates). Different letters indicate significant difference by one-way ANOVA $(\mathrm{P}<0.05)$.

(E) EMSA assay. The 26 bp cis-element containing CArG motifsof MYB102 promoter was synthesized with biotin labelled at the $5^{\prime}$ end. Non-labelled probes was used as competitor. As indicated, AGL16-dependent mobility shifts were competed by the competitor probe in a dose-dependent manner.

\section{Figure 10. HsfA6a genetically acts downstream of AGL16}

(A-C) Seed germination of Col-0, agl16, hsfa6a, and agll6 hsfa6a lines. Vernalized seeds were germinated on MS medium with or without $120 \mathrm{mM} \mathrm{NaCl}, 250 \mathrm{mM}$ mannitol, or $0.5 \mu \mathrm{M}$ ABA for 7 days before photographs were taken (A). Seed germination rate was counted at the indicated time points (B). Green cotyledon rate was counted at 7 days of germination $(C)$. Values are mean \pm SD ( $n=3$ replicates, 60 seeds/replicate). Different letters indicate significant difference by one-way ANOVA $(\mathrm{P}<0.05)$.

(D-E) Primary root elongation of Col-0, agll6, hsfa6a, and agll6 hsfa6a lines. Seeds were germinated on MS medium for 4 days respectively, and then seedlings were transferred to MS medium with or without $120 \mathrm{mM} \mathrm{NaCl}, 250 \mathrm{mM}$ mannitol, or $5 \mu \mathrm{M}$ ABA and grown vertically for 7 days before photographs were taken (D) and primary root length was measured (E). Values are mean $\pm S D(n=3$ replicates 30 seedlings/replicate). Different letters indicate significant difference by one-way ANOVA $(\mathrm{P}<0.05)$.

\section{Figure 11. MYB102 genetically acts downstream of $A G L 16$}

(A-C) Seed germination of Col-0, agl16, myb102, and agl16 myb102 lines. Vernalized seeds were horizontally germinated on MS medium with or without $120 \mathrm{mM} \mathrm{NaCl}$, $250 \mathrm{mM}$ mannitol, or $0.5 \mu \mathrm{M}$ ABA for 7 days before photographs were taken (A). Seed germination rate was counted at the indicated time points (B). Green cotyledon 
1082 rate was counted at 7 days of germination (C). Values are mean $\pm S D(n=3$ replicates,

108360 seeds/replicate). Different letters indicate significant difference by one-way

1084 ANOVA $(\mathrm{P}<0.05)$.

1085 (D-E) Primary root elongation of Col-0, agl16, myb102, and agl16 myb102 lines.

1086 Seeds were germinated on MS medium for 4 days respectively, and then seedlings

1087 were transferred to MS medium with or without $120 \mathrm{mM} \mathrm{NaCl}, 250 \mathrm{mM}$ mannitol, or

$10885 \mu \mathrm{M}$ ABA and grown vertically for 7 days before photographs were taken (D) and

1089 primary root length was measured $(\mathrm{E})$. Values are mean $\pm \mathrm{SD}(\mathrm{n}=3$ replicates, 30

1090 seedlings/replicate). Different letters indicate significant difference by one-way

1091 ANOVA $(\mathrm{P}<0.05)$.

1092

1093 

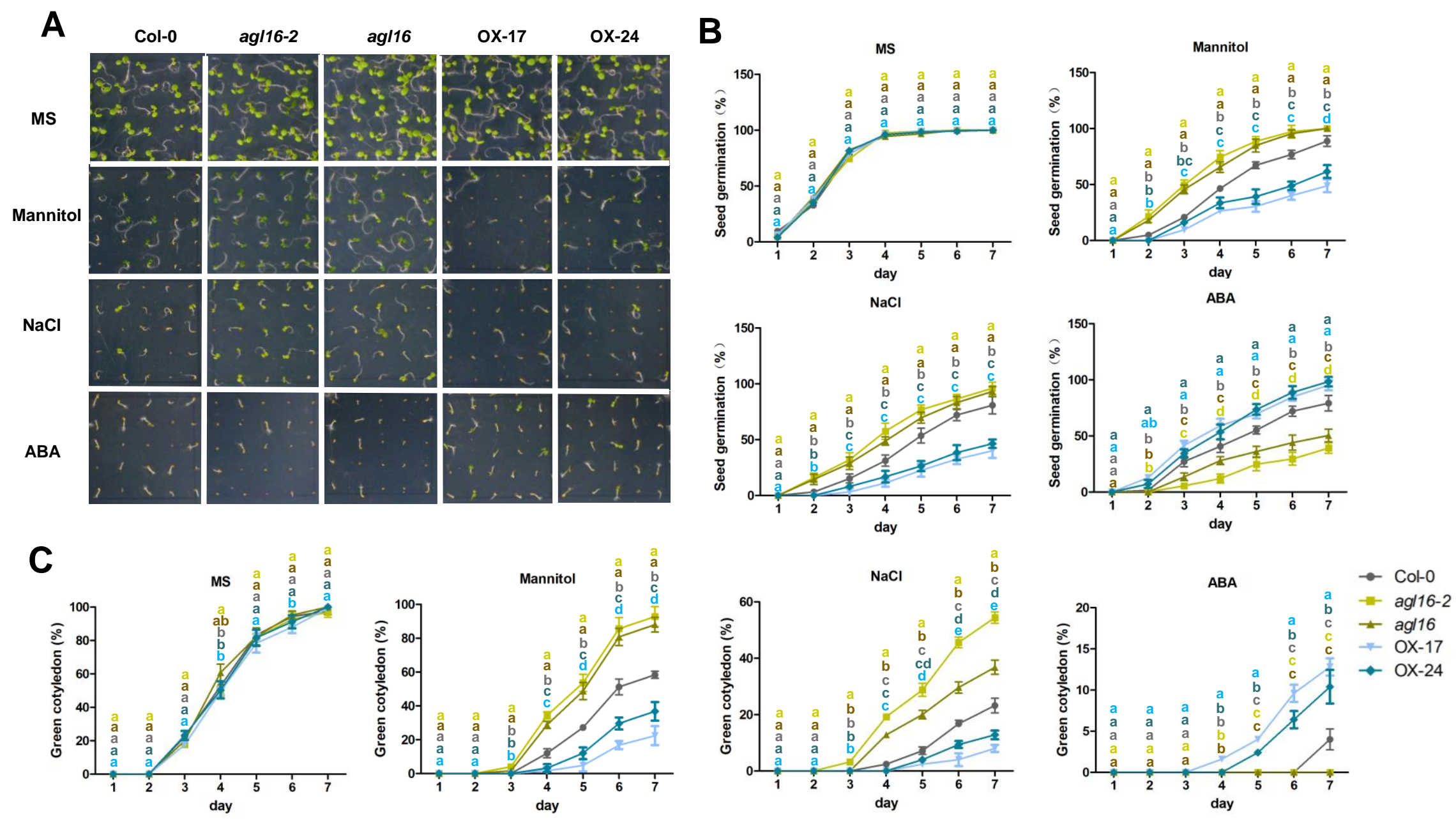

Figure 1. Response of $A G L 16$ to abiotic stress in seed germination

(A-C) Seed germination of Col-0, agl16-2, agl16, and AGL16 overexpression (OX) lines. Seeds were horizontally germinated on MS medium with or without $120 \mathrm{mM} \mathrm{NaCl}, 250 \mathrm{mM}$ mannitol and $0.5 \mu \mathrm{M}$ ABA for 7 days. Photographs were taken (A). Seed germination rate was measured at the indicated time points (B). Green cotyledon rate was measured every day for 7 days (C). Values are mean \pm SD (n=3 replicates, 60 seeds/replicate). Different letters indicate significant difference by one-way ANOVA $(\mathrm{P}<0.05)$. 

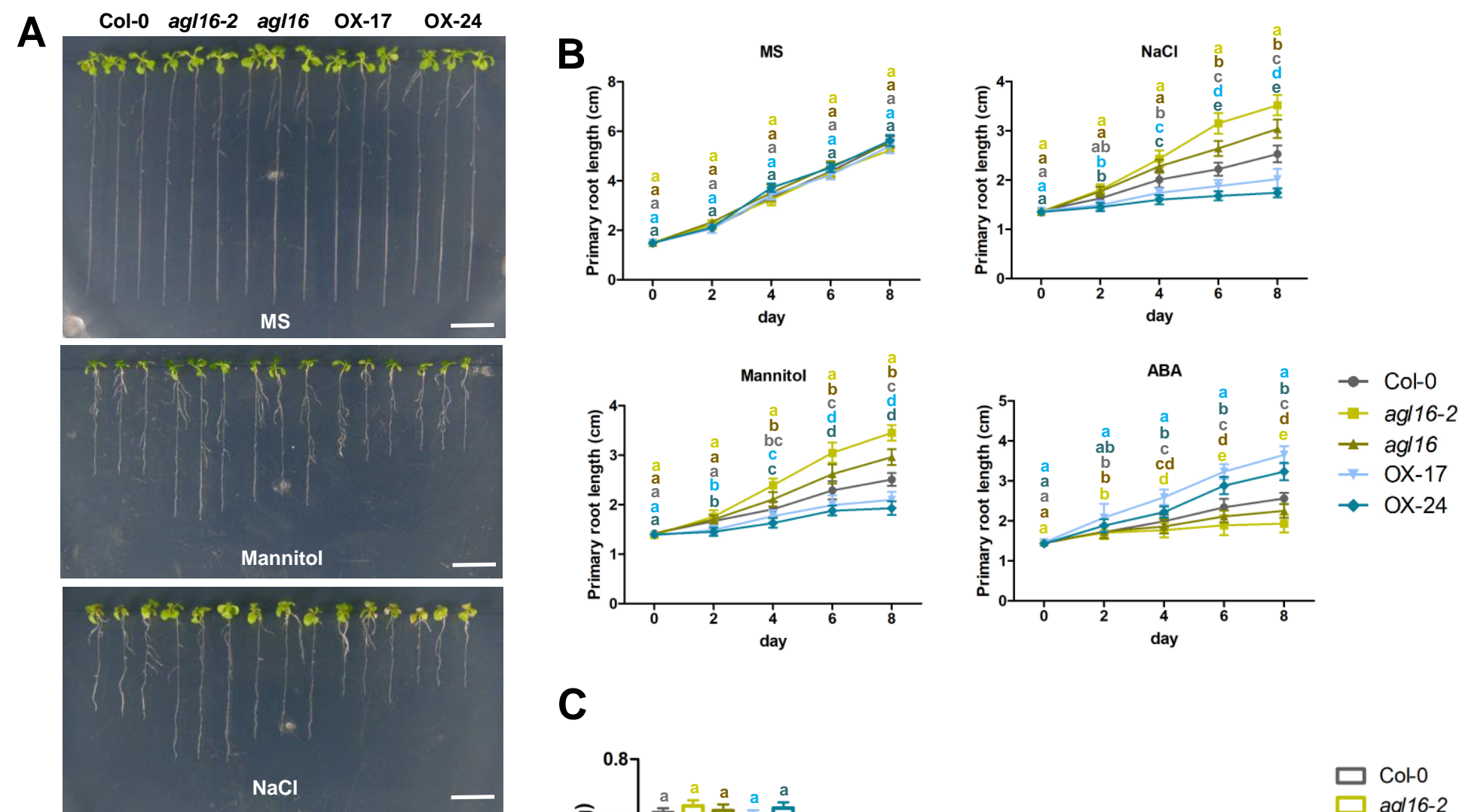

C
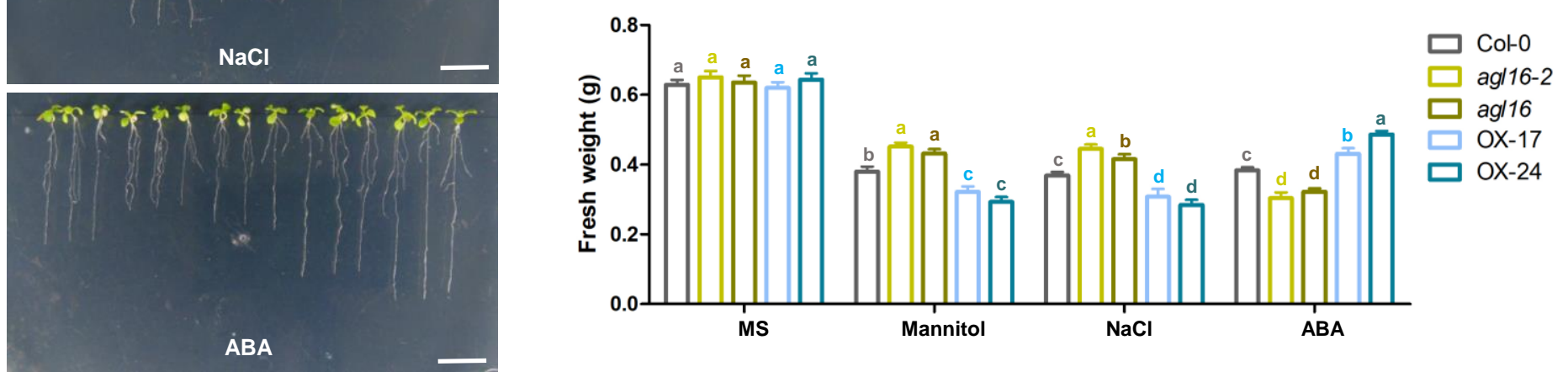

Figure 2. Primary root elongation of agl16 mutants and AGL16 overexpression lines in response to abiotic stress.

(A-B) Primary root elongation. Seeds of Col-0, agl16-2, agl16, and OX lines were germinated on MS medium for 4 days respectively, then seedlings were transferred to MS medium with or without $120 \mathrm{mM} \mathrm{NaCl}, 250 \mathrm{mM}$ mannitol and $5 \mu \mathrm{M}$ ABA for 8 days. Photographs were taken (A) and primary root length was measured at the indicated time points (B). Values are the mean $\pm \mathrm{SD}$ ( $\mathrm{n}=3$ replicates, 30 seedlings/replicate). Different letters indicate significant difference by one-way ANOVA $(\mathrm{P}<0.05)$.

(C) The fresh weights. The fresh weights of 12-day-old seedlings of Col-0, agll6-2, agl16, and OX lines were measured. Values are mean \pm $\mathrm{SD}(\mathrm{n}=3$ replicates, 30 seedlings/replicate). Different letters indicate significant difference by one-way ANOVA $(\mathrm{P}<0.05)$. 


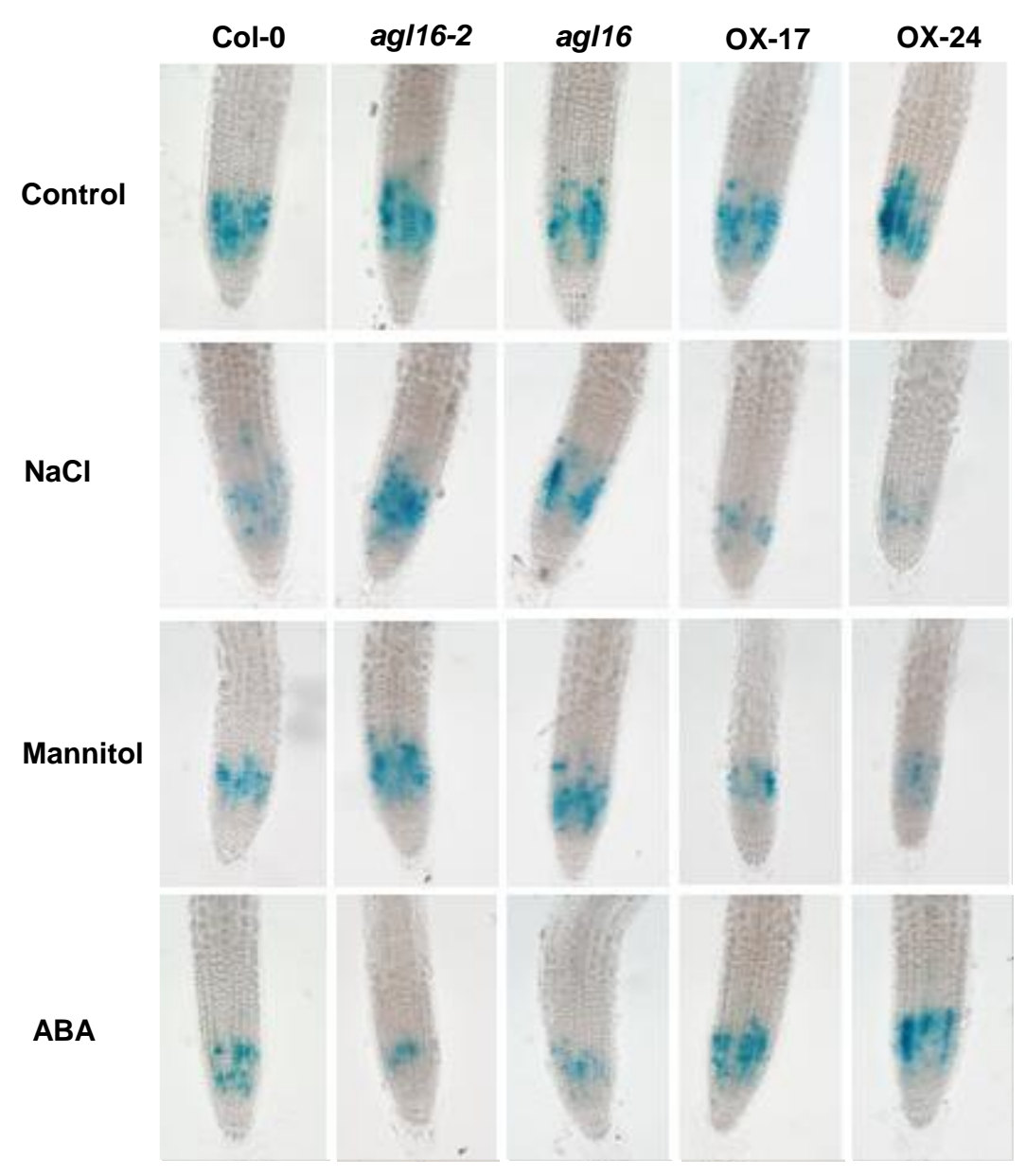

Figure 3. CyclinB1;1 activity in primary root of Col-0, agl16-2, agl16, and AGL16 overexpression lines.

The CyclinB1;1-GUS maker was introduced in Col-0, agl16-2, agl16, and OX lines background by genetic crossing. The seeds were germinated on MS medium for 4 days, then seedlings were respectively transferred to MS medium with or without $120 \mathrm{mM} \mathrm{NaCl}, 250 \mathrm{mM}$ mannitol, $5 \mu \mathrm{M}$ ABA and grown for 3 days before GUS staining. Seedlings ( $>20$ ) were incubated in GUS solution for 5 hours before photographs were taken. Bar=100 $\mu \mathrm{m}$. 

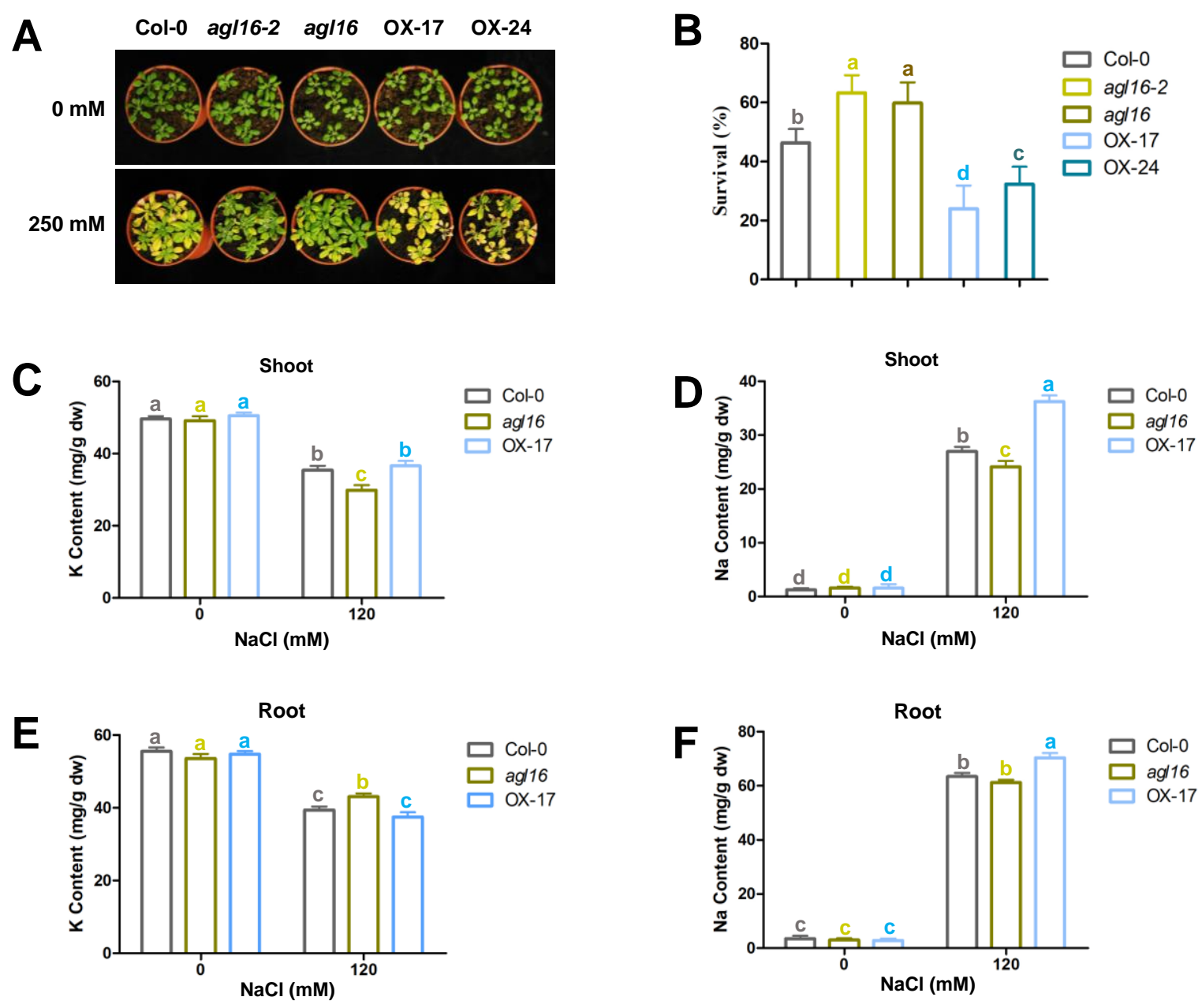

Figure 4. AGL16 negatively modulates salt tolerance in Arabidopsis plants grown in soil.

(A-B) Salt tolerance assay in soil. 3-week old soil-grown seedlings of Col-0, agl16-2, agl16, and OX lines were irrigated with or without 250 $\mathrm{mM} \mathrm{NaCl}$ for 2 weeks. Photographs were taken (A) and survival rate was calculated (B). Values are mean \pm SD ( $\mathrm{n}=3$ replicates, 60 seedlings/replicate). Different letters indicate significant difference by one-way ANOVA $(\mathrm{P}<0.05)$.

(C-F) Ion accumulation in salt-treated Col-0, agl16, OX-17 plants. Seeds of Col-0, agl16, OX-17 lines were respectively germinated on MS medium for 4 days, then seedlings were transferred to MS medium with or without $120 \mathrm{mM} \mathrm{NaCl}$ and grown vertically for 10 days. Sodium, potassium content were quntified in shoots (C-D) and roots (E-F). Values are mean $\pm \mathrm{SD}$ ( $\mathrm{n}=3$ replicates, 50 seedlings/replicate). Different letters indicate significant difference by one-way ANOVA $(\mathrm{P}<0.05)$. 
A
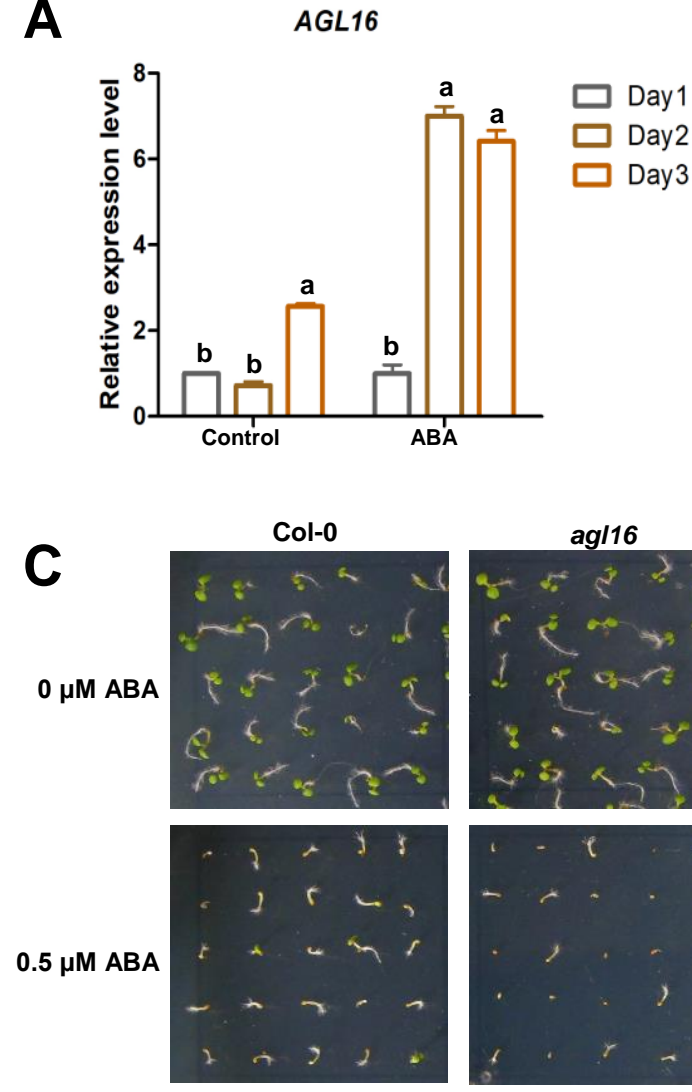

D

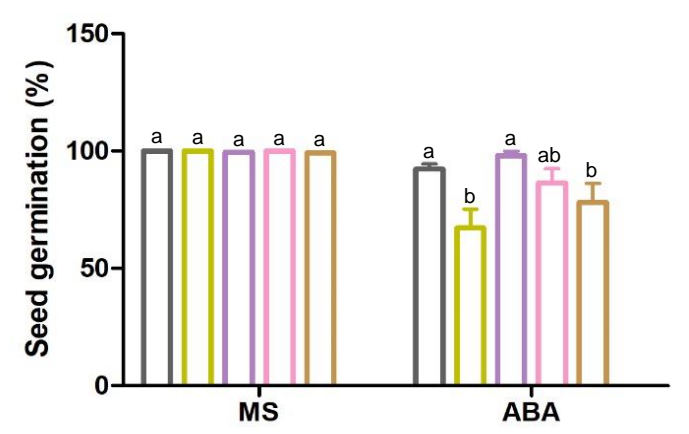

B
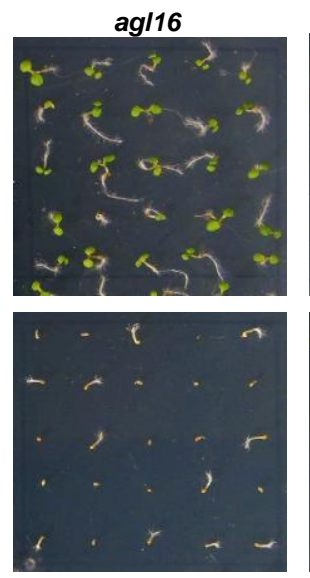

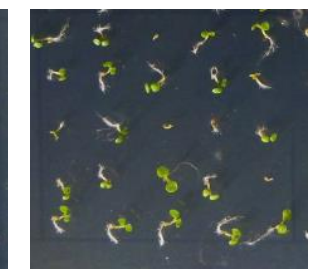

$\mathbf{E}$

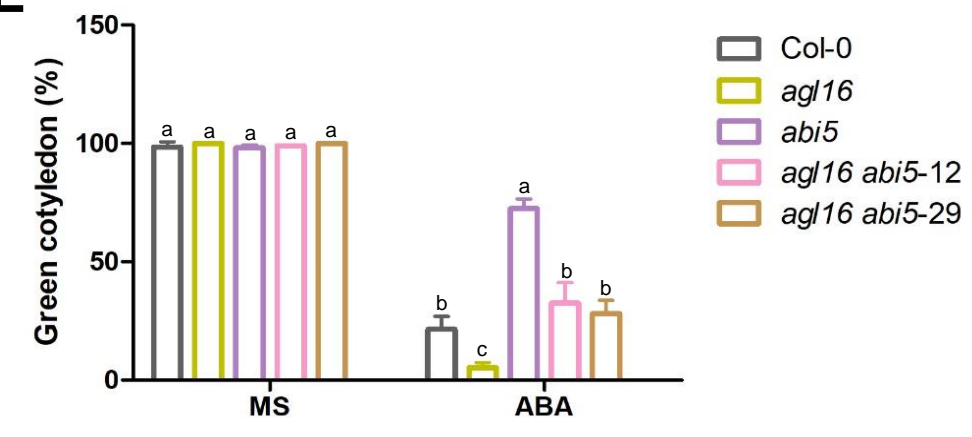

Figure 5. AGL16 expression is dependent on ABA signaling in seed germination.

(A) The response of AGL16 expression to ABA in seeds. Vernalized wild type (Col-0) seeds were germinated on MS medium without (control) or with $0.5 \mu \mathrm{M}$ ABA for 1, 2, 3 days. RNA was extracted from seeds and the transcript level of AGL16 was analyzed by qRT-PCR. Values are mean $\pm \mathrm{SD}$ ( $\mathrm{n}=3$ replicates). Different letters indicate significant difference by one-way ANOVA $(\mathrm{P}<0.05)$.

(B) Transcript levels of AGL16 in abi mutants. Vernalized seeds of Col-0, abi1-1, abi2-2, abi3-8, abi4-1, and abi5-7 were germinated on MS medium without (control) or with $0.5 \mu \mathrm{M}$ ABA for 24 hours, respectively. RNA was extracted and the transcript level of $A G L 16$ was detected by qRT-PCR. Values are mean $\pm \mathrm{SD}$ ( $\mathrm{n}=3$ replicates).

(C-E) AGL16 acts upstream of ABI5. Seeds of Col-0, agl16, abi5, agl16 abi5 lines were horizontally germinated on MS medium with or without $0.5 \mu \mathrm{M}$ ABA for 7 days. Photographs were taken (C). Seed germination rate (D) and green cotyledon rate were measured at 7 days after the end of stratification (E). Values are mean $\pm \mathrm{SD}$ ( $\mathrm{n}=3$ replicates, 60 seeds/ replicates). Different letters indicate significant difference by one-way ANOVA $(\mathrm{P}<0.05)$. 
A

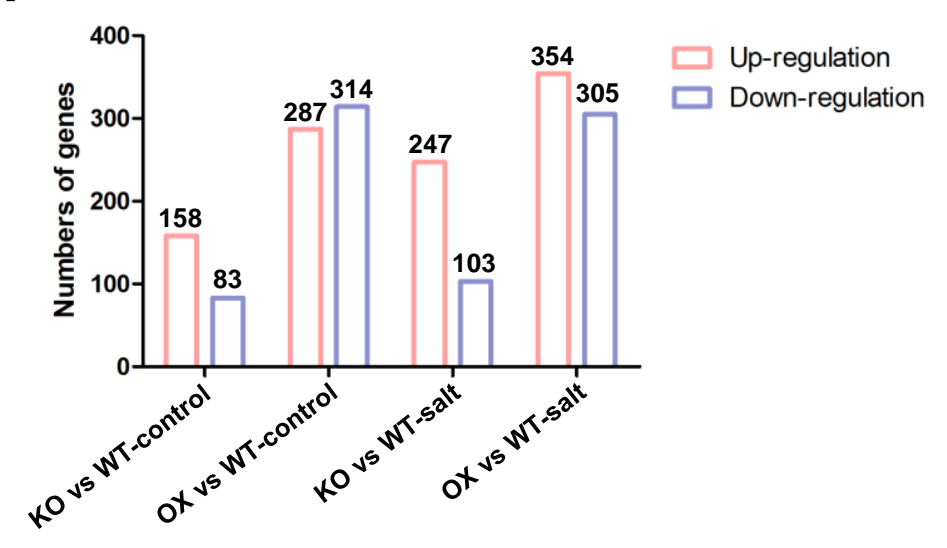

B

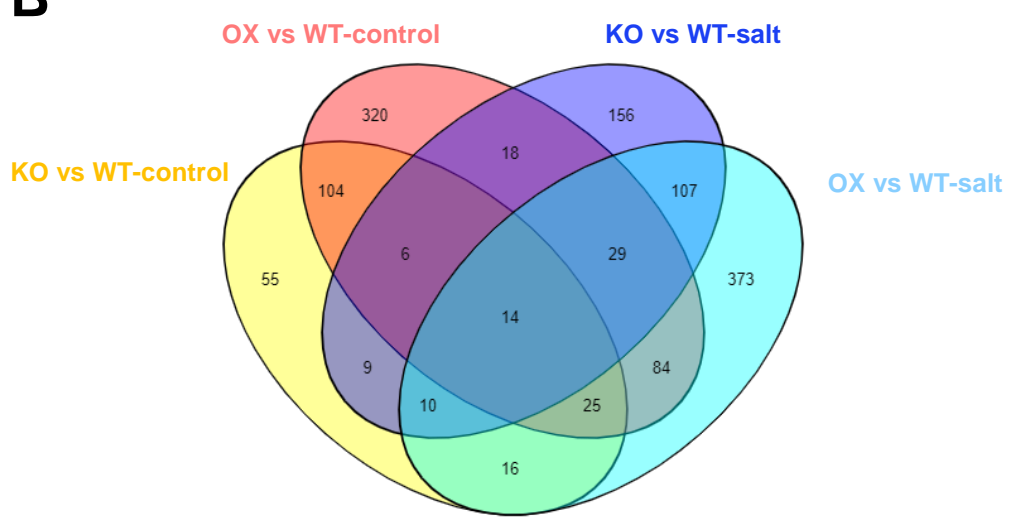

C
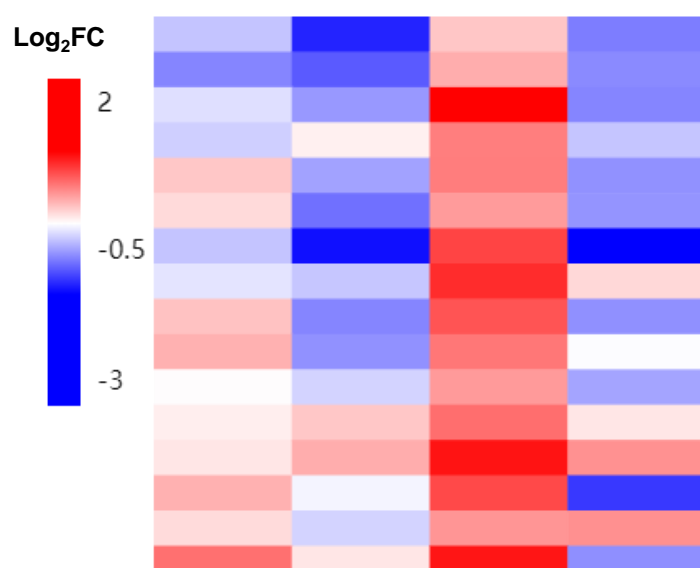

- AT5G52310

AT5G52300

- АT3G14440 AT5G66400

AT5O1596

AT5G15970

AT2G42530

AT5G05410

AT2G36270

AT4G34000

- AT1G05100

AT3G15500

- AT1G52890

AT5G 43840

AT3G22830

AT1G27730

AT5G04340

AT5G468

AT5G49450

AT2G03150

- AT3G05030

- AT4G13420

AT4G10310

AT2G38170

- AT3G51860

- AT4G23700

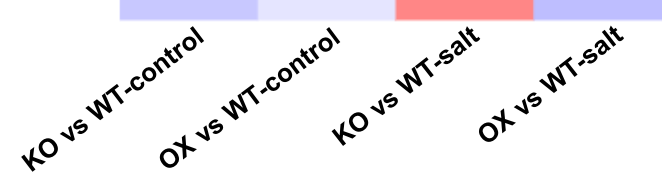

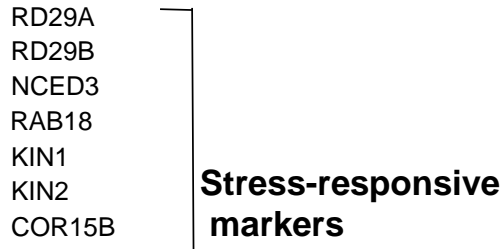

DREB2A

ABI5

ABF3

MAPKKK18 -

NAC055

NAC019

MYB102

MYB41

HsfA6a

HsfA6b

ZAT10

ZAT6

MYC5

bZIP1

RSA 1

$\mathrm{NHX} 2$

HAK5

HKT1

CAX1

CAX3

$\mathrm{CHX} 17$

\section{markers}

\section{Transcription factors}

Ion transport

Figure 6. Transcriptomic analyses of differentially expressed genes (DEGs) affected by AGL16.

(A) The number of differentially expressed genes (DEGs). The statistics data of differentially expressed genes in (KO vs WT)-control, (OX vs WT)-control and (KO vs WT)-salt, (OX vs WT)-salt groups.

(B) Comparison of differentially expressed genes (DEGs) among (KO vs WT)-control, (OX vs WT)-control (KO vs WT)-salt, and (OX vs WT)-salt groups using Venn diagram. The numbers represent the total numbers of differentially expressed genes in different comparison groups.

(C) Hierarchical clustering analysis of salt stress-related genes affected by AGL16 in DEGs. The heatmap represents fold changes in the abundance of gene transcripts in different comparison groups. 


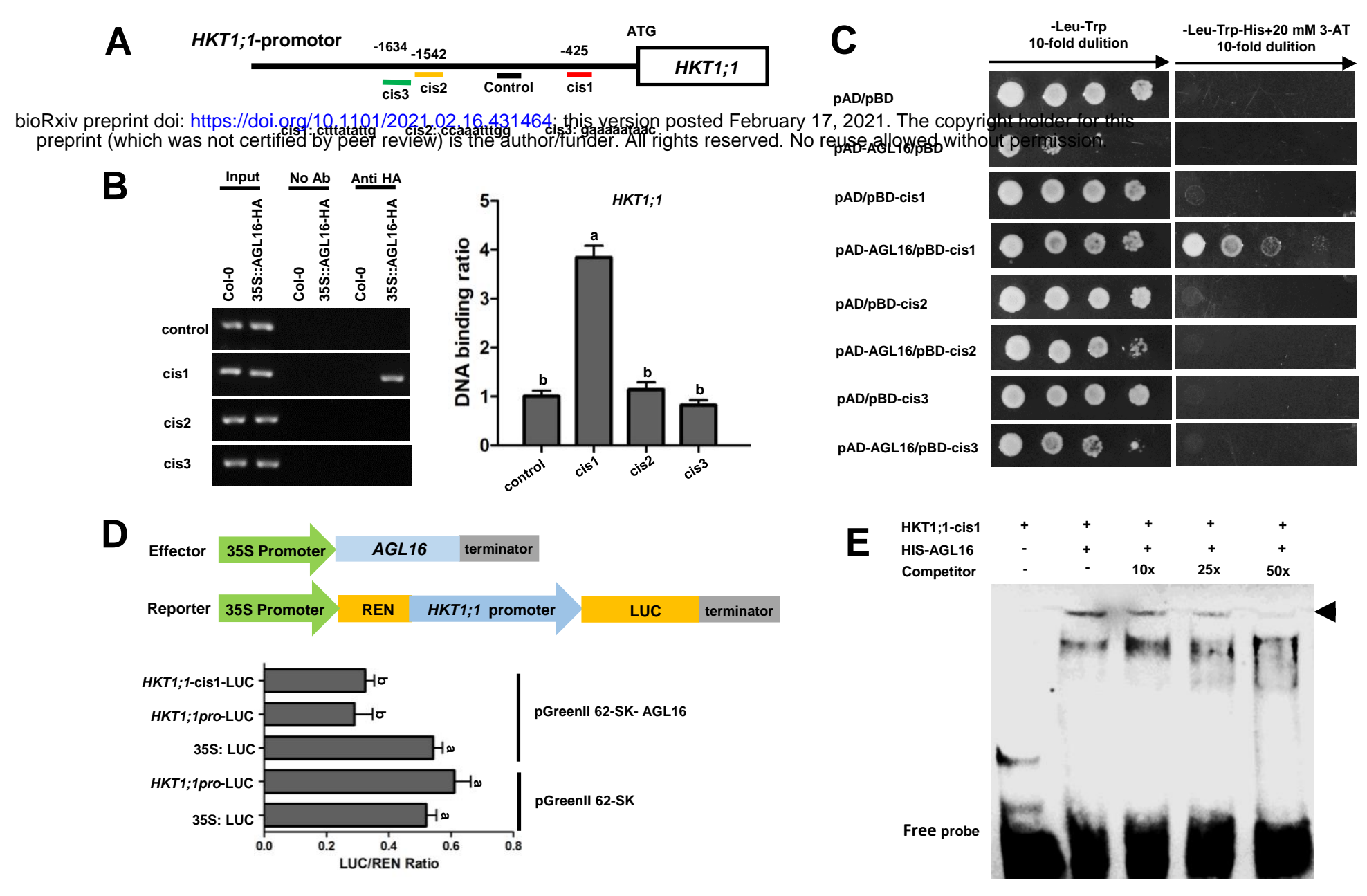

\section{Figure 7. AGL16 binds to the CArG motif in the promoter of HKT1;1.}

(A) Schematic illustration of $H K T 1 ; 1$ promoter with AGL16 candidate CArG motifs. The number represents the location of CArG motifs in HKT1;1 promoter; Short lines of different colors mark the regions amplified in PCR and qRT-PCR analyses, while the black line represents the control region without CArG motifs.

(B) ChIP-PCR assay. 7-day-old 35S:HA-AGL16 transgenic plants and wild type (Col-0) were used for the ChIP-PCR assay. A region of $H K T 1 ; 1$ that does not contain CArG motifs was used as a control. About $200 \mathrm{bp}$ fragment cis 1 from $H K T 1 ; 1$ promoter containing the CArG motif was enriched by anti-HA antibodies as shown in PCR and qRT-PCR analyses. Values are mean \pm $\mathrm{SD}(\mathrm{n}=3$ replicates). Different letters indicate significant difference by one-way ANOVA $(\mathrm{P}<0.05)$.

(C) Yeast one-hybrid assay. The coding sequence of AGL16 was constructed into pGADT7 (pAD) and the 26 bp fragment containing the CArG motif of $H K T 1 ; 1$ promoter was cloned into pHIS2 (pBD). Different yeast culture dilutions (1:1, 1:10, 1:100, 1:1,000) were grown on SD/-Trp-Leu medium with or without His plus $20 \mathrm{mM}$ 3-AT. pAD/pBD, pAD-AGL16/pBD, pAD/pBDcis1, pAD/pBD-cis2, pAD/pBD-cis3 were used as negative controls.

(D) Transient transactivation assays. Schematic illustration of the effector and reporters used in the transient transactivation assays. AGL16 effector were under the control of the CaMV 35S promoter. HKT1;1 promoter and the 26 bp binding cis-element of $H K T 1 ; 1$ promoter were respectively fused to the LUC gene as reporters. The firefly LUC and REN activities luciferase were detected by transient dual-luciferase reporter assays, and LUC/REN ratio was calculated. The REN activity was used as an internal control. Values are mean $\pm \mathrm{SD}$ ( $\mathrm{n}=3$ replicates). Different letters indicate significant difference by one-way ANOVA (P $<0.05)$.

(E) EMSA assay. The 26 bp cis-element containing the CArG motif of HKT1;1 promoter was synthesized with biotin labelled at the 5' end. Non-labelled probe was competitor. As indicated, AGL16-dependent mobility shifts were competed by the competitor probe in a dose-dependent manner. 


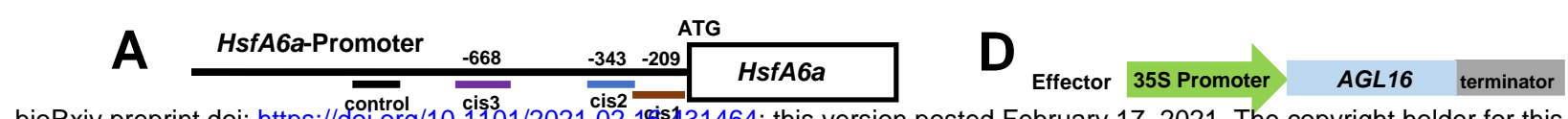
bioRxiv preprint doi: https://dol.org/10.1101/2021.02.18js.431464; this version posted February 17, 2021. The copyright holder for this

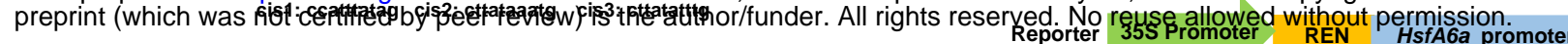
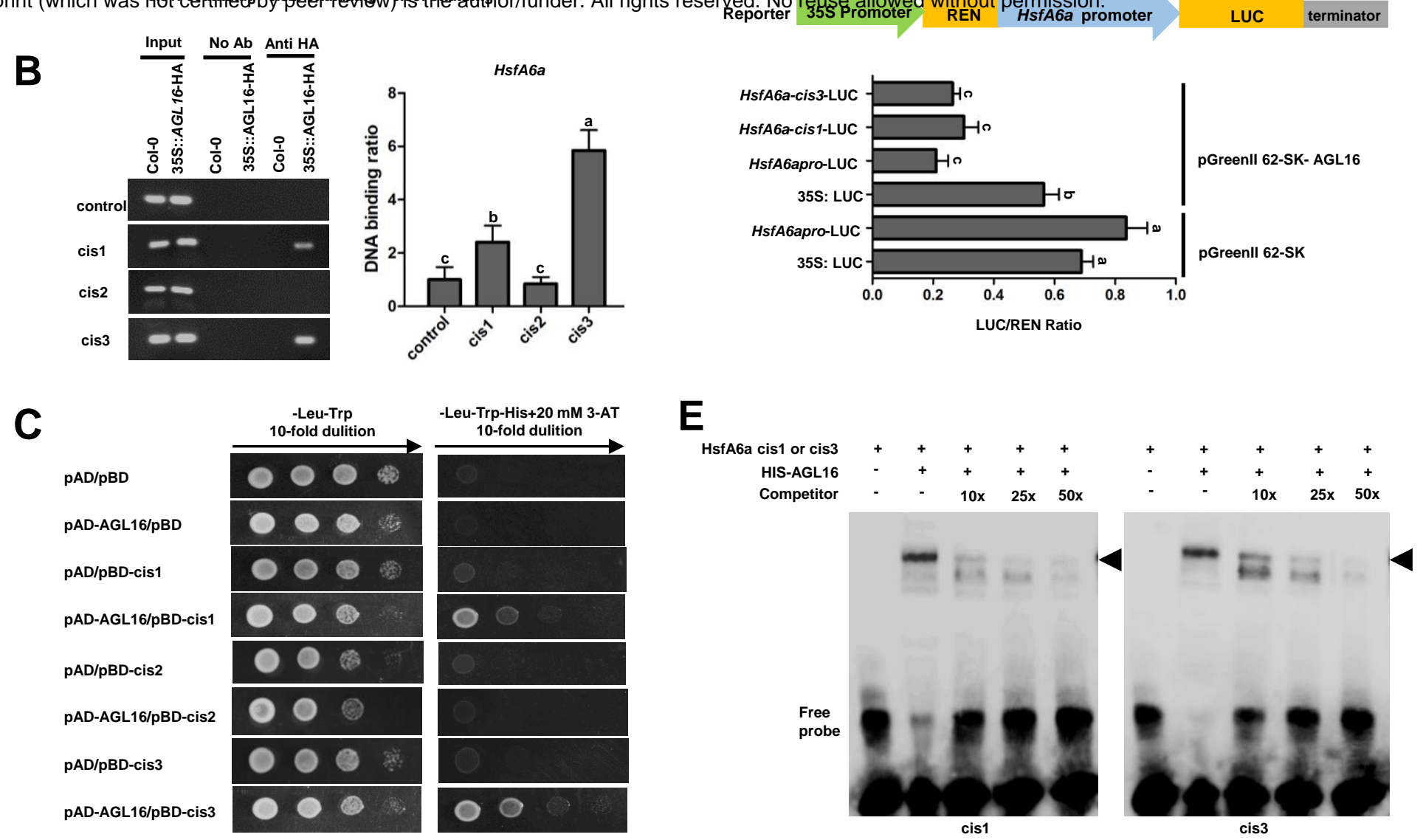

Figure 8. AGL16 binds to the CArG motifs in the promoter of HsfA6a.

(A) Schematic illustration of HsfA6a promoter with candidate CArG motifs. The number represents the location of CArG motifs in HsfA6a promoter; Short lines of different colors mark the regions amplified in PCR and qRT-PCR analyses, while the black line represents the control region without CArG motifs.

(B) ChIP-PCR assay. 7-day-old 35S:HA-AGL16 transgenic plants and wild type (Col-0) were used for the ChIP-PCR assay. A region of HsfA6a that does not contain CArG motifs was used as a control. About 200 bp fragment cis1 and cis3 from HsfA6a promoter containing CArG motifs were enriched by anti-HA antibodies as shown in PCR and qRT-PCR analyses. Values are mean $\pm \mathrm{SD}$ ( $\mathrm{n}=3$ replicates). Different letters indicate significant difference by one-way ANOVA $(\mathrm{P}<0.05)$.

(C) Yeast one-hybrid assay. The coding sequence of AGL16 was constructed into pGADT7 (pAD) and the 26 bp fragment containing the CArG motif of HsfA6a promoter was cloned into pHIS2 (pBD). Different yeast culture dilutions (1:1, 1:10, 1:100, 1:1,000) were grown on SD/-Trp-Leu medium with or without His plus $20 \mathrm{mM} 3$-AT. pAD/pBD, pAD-AGL16/pBD, pAD/pBDcis1, pAD/pBD-cis2, pAD/pBD-cis3 were used as negative controls.

(D) Transient transactivation assays. Schematic illustration of the effector and reporters used in the transient transactivation assays. AGL16 effector were under the control of the CaMV 35S promoter. HsfA6a promoter and the 26 bp cis-elements of $H s f A 6 a$ promoter were respectively fused to the LUC gene as reporters. The firefly LUC and REN activities luciferase were detected by transient dual-luciferase reporter assays, and LUC/REN ratio was calculated. The REN activity was used as an internal control. Values are mean $\pm \mathrm{SD}$ ( $\mathrm{n}=3$ replicate). Different letters indicate significant difference by one-way ANOVA $(\mathrm{P}<0.05)$.

(E) EMSA assay. The 26 bp cis-element containing CArG motif of HsfA6a promoter were synthesized with biotin labelled at the 5' end. Non-labelled probe was used as competitor. As indicated, AGL16-dependent mobility shifts were competed by the competitor probe in a dose-dependent manner. 

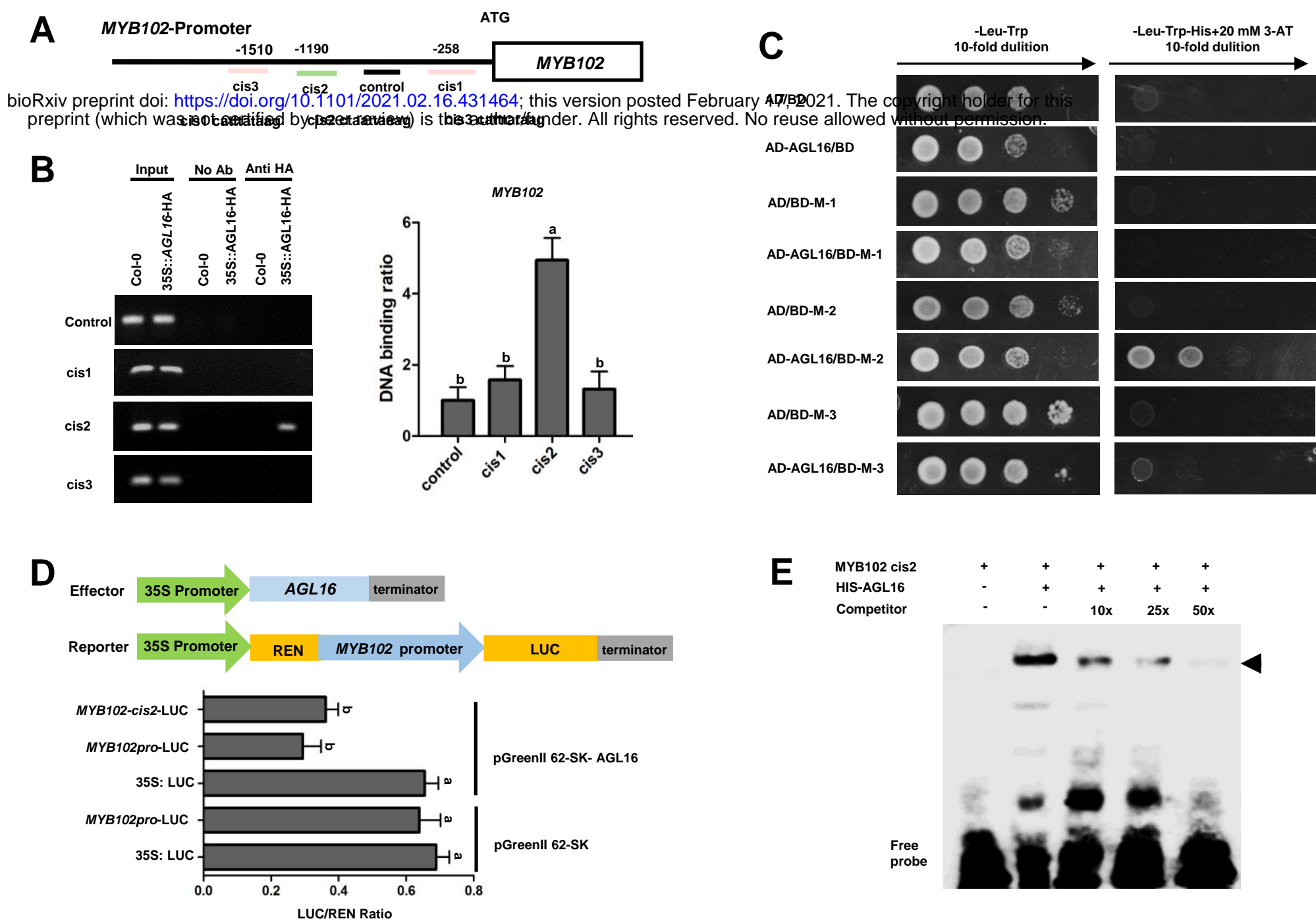

Figure 9. AGL16 binds to the CArG motifs in the promoter of MYB102.

(A) Schematic illustration of MYB102 promoter with AGL16 candidate CArG motifs. The number represents the location of CArG motifs in MYB102 promoter; Short lines of different colors mark the regions amplified in PCR and qRT-PCR analyses, while the black line represents the control region without CArG motifs.

(B) ChIP-PCR assay. 7-day-old 35S:HA-AGL16 transgenic plants and wild type (Col-0) were used for the ChIP-PCR assay. A region of MYB102 that does not contain CArG motifs was used as a control. About $200 \mathrm{bp}$ fragment cis 2 from MYB102 promoter containing CArG motifs was enriched by anti-HA antibodies as shown in PCR and qRT-PCR analyses. Values are mean \pm SD (n=3 replicates).

Different letters indicate significant difference by one-way $\operatorname{ANOVA}(\mathrm{P}<0.05)$.

(C) Yeast one-hybrid assay. The coding sequence of AGL16 was constructed into pGADT7 (pAD) and the 26 bp fragment containing CArG motif of MYB102 promoter was cloned into pHIS2 (pBD). Different yeast culture dilutions $(1: 1,1: 10,1: 100,1: 1,000)$ were grown on SD/-Trp-Leu medium with or without His plus 20 mM 3-AT. pAD/pBD, pAD-AGL16/pBD, pAD/pBD-cis1, pAD/pBDcis $2, \mathrm{pAD} / \mathrm{pBD}$-cis3 were used as negative controls.

(D) Transient transactivation assays. Schematic illustration of the effector and reporters used in the transient transactivation assays. AGL16 effector were under the control of the CaMV 35S promoter. MYB102 promoter and the 26 bp cis-element of MYB102 promoter were respectively fused to the LUC gene as reporters. The firefly LUC and REN activities luciferase were detected by transient dual-luciferase reporter assays, and LUC/REN ratio was calculated. The REN activity was used as an internal control. Values are mean $\pm \mathrm{SD}$ (n=3 replicates). Different letters indicate significant difference by one-way ANOVA (P $<0.05)$.

(E) EMSA assay. The 26 bp cis-element containing CArG motifsof MYB102 promoter was synthesized with biotin labelled at the 5' end. Non-labelled probes was used as competitor. As indicated, AGL16-dependent mobility shifts were competed by the competitor probe in a dose-dependent manner. 
A
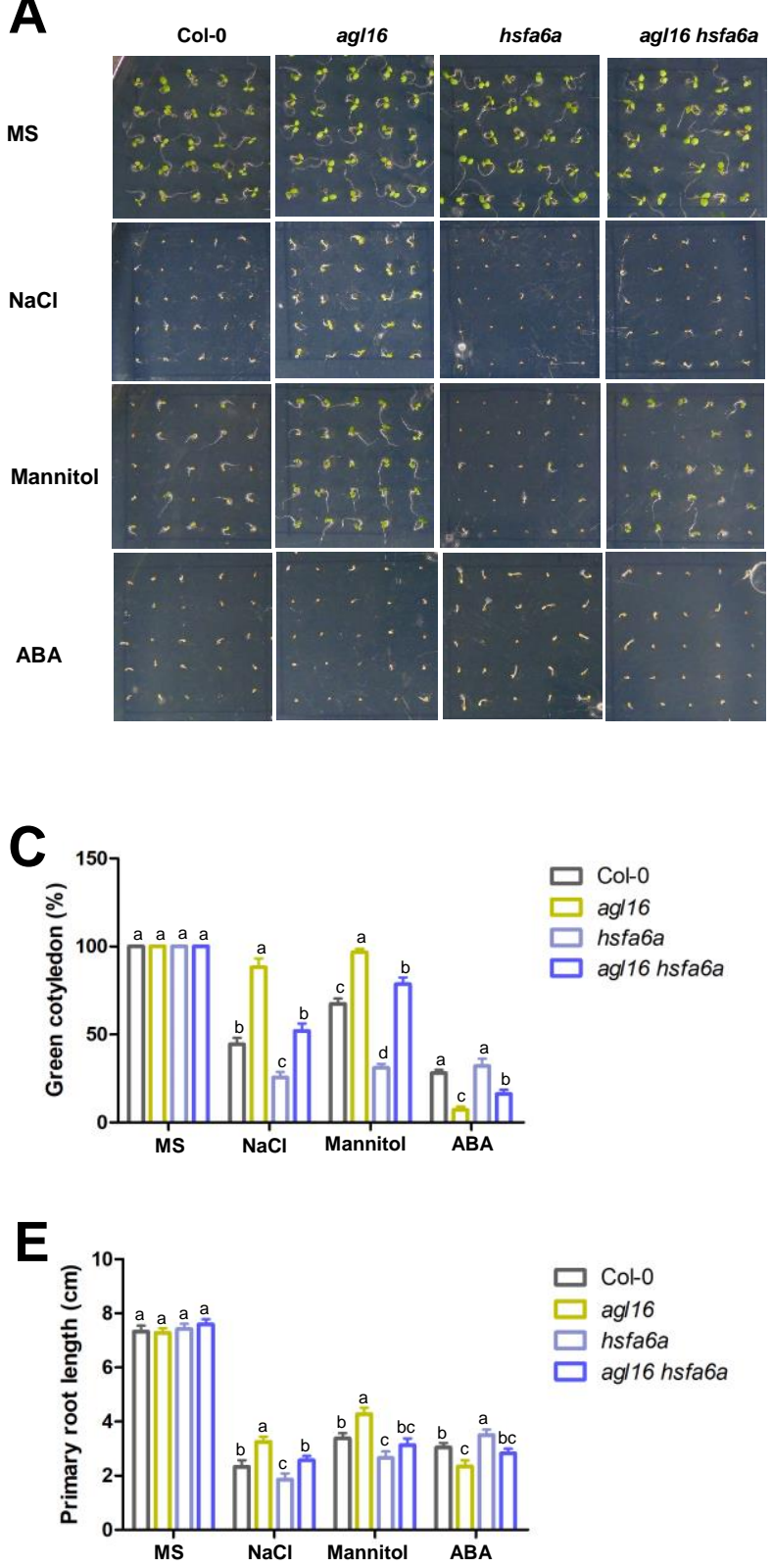

B
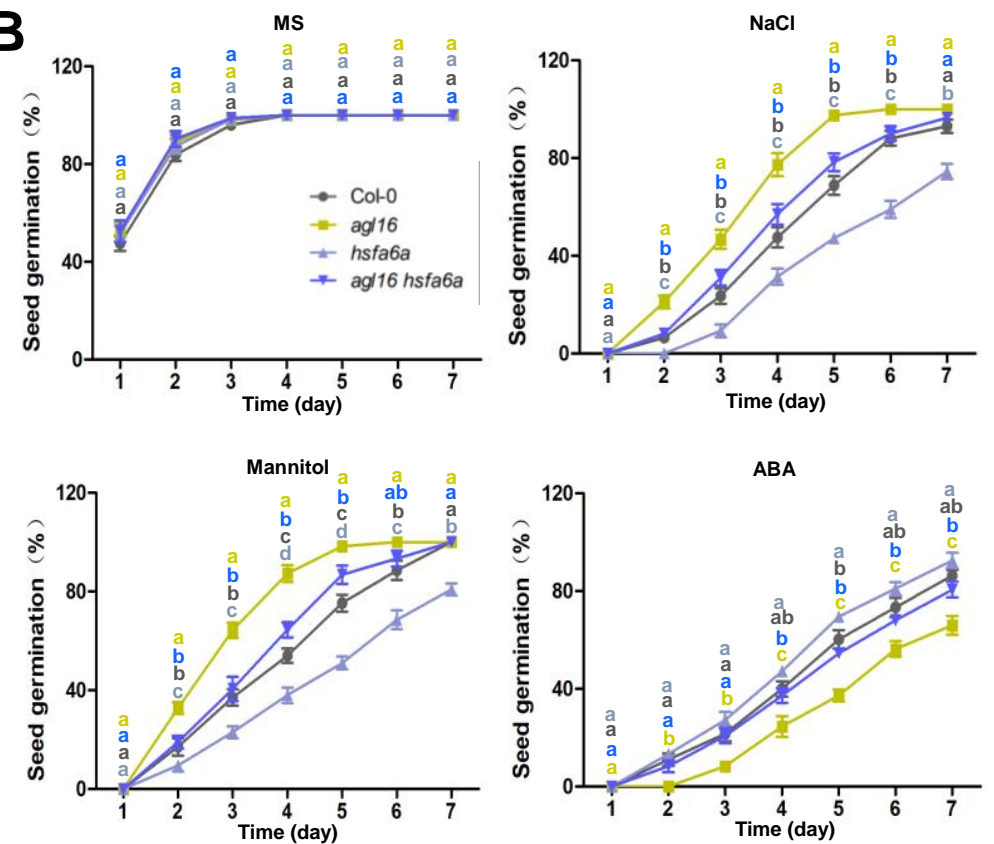

D
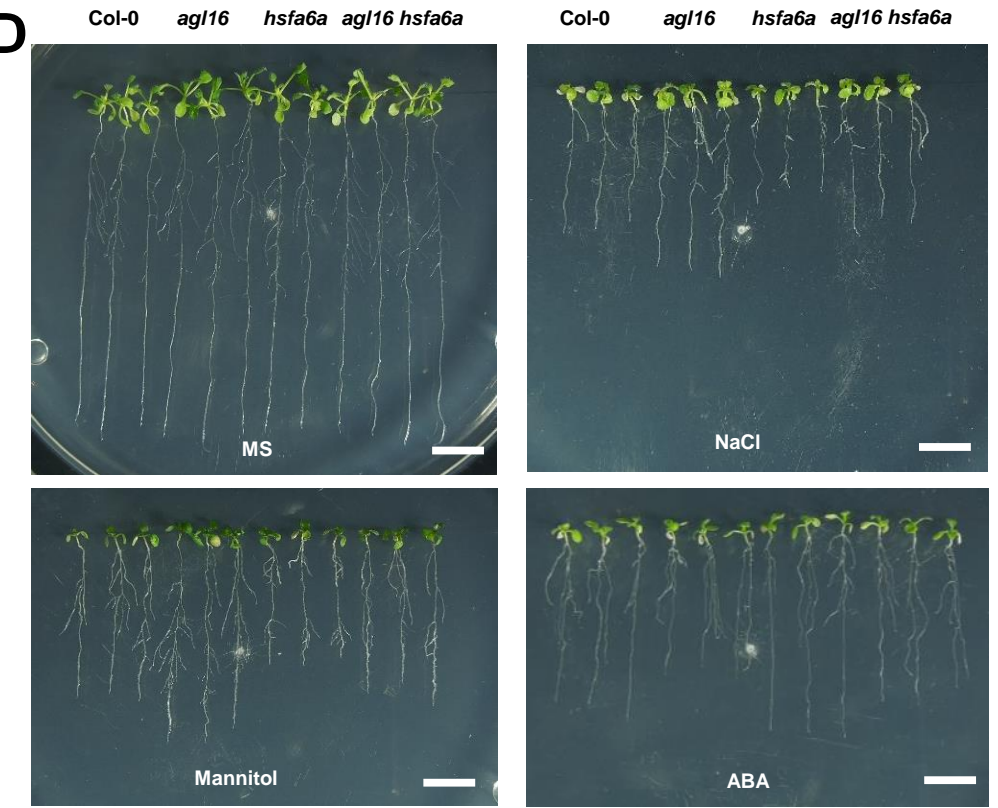

\section{Figure 10. HsfA6a genetically acts downstream of $A G L 16$}

(A-C) Seed germination of Col-0, agl16, hsfa6a, and agll6 hsfa6a lines. Vernalized seeds were germinated on MS medium with or without $120 \mathrm{mM} \mathrm{NaCl}, 250 \mathrm{mM}$ mannitol, or $0.5 \mu \mathrm{M}$ ABA for 7 days before photographs were taken (A). Seed germination rate was counted at the indicated time points (B). Green cotyledon rate was counted at 7 days of germination (C). Values are mean \pm $\mathrm{SD}$ ( $\mathrm{n}=3$ replicates, 60 seeds/replicate). Different letters indicate significant difference by one-way ANOVA $(\mathrm{P}<0.05)$.

(D-E) Primary root elongation of Col-0, agll6, hsfa6a, and agll6 hsfa6a lines. Seeds were germinated on MS medium for 4 days respectively, and then seedlings were transferred to MS medium with or without $120 \mathrm{mM} \mathrm{NaCl}, 250 \mathrm{mM}$ mannitol, or $5 \mu \mathrm{M}$ ABA and grown vertically for 7 days before photographs were taken (D) and primary root length was measured (E). Values are mean \pm $\mathrm{SD}(\mathrm{n}=3$ replicates 30 seedlings/replicate). Different letters indicate significant difference by one-way ANOVA $(\mathrm{P}<0.05)$. 

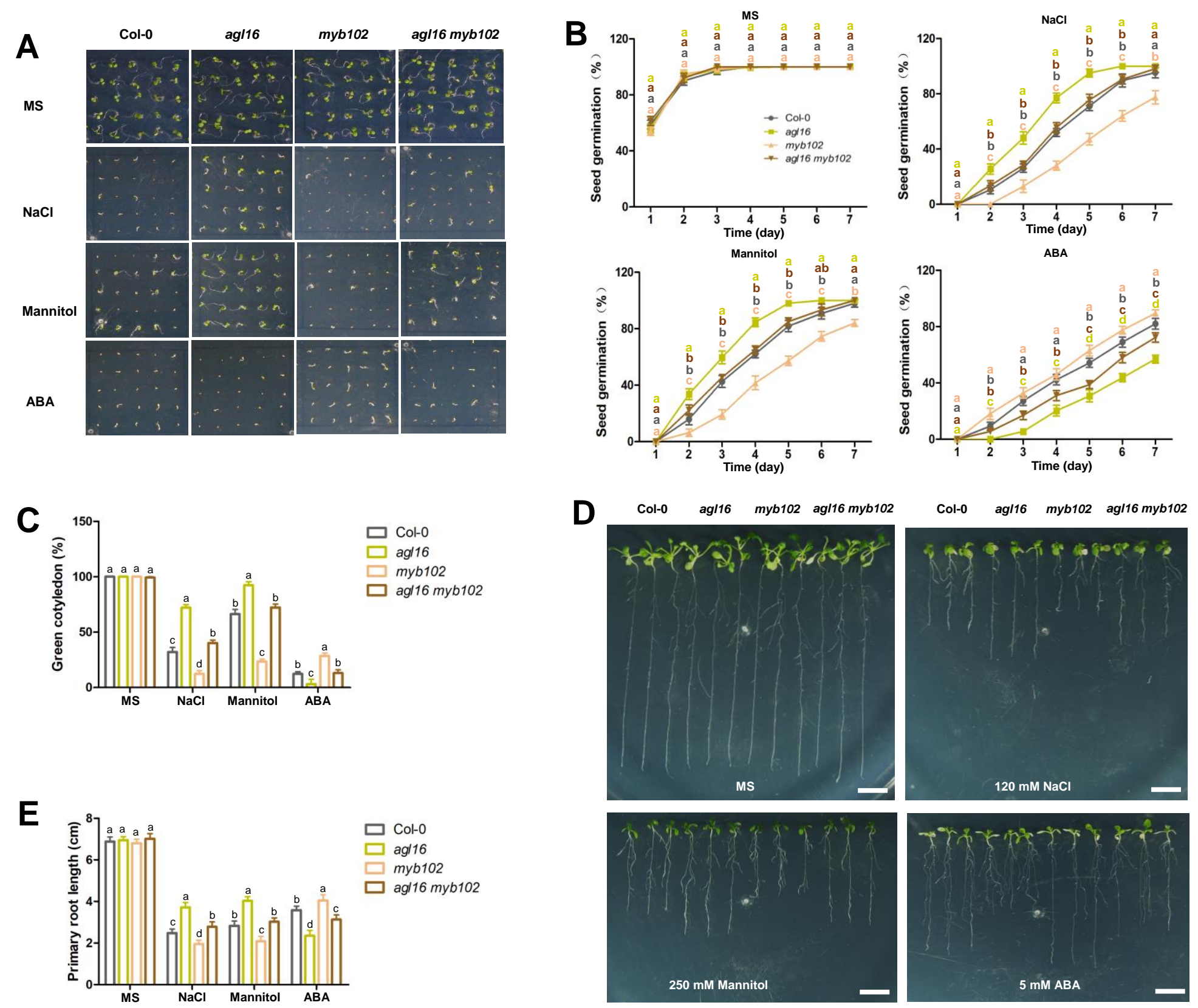

\section{Figure 11. MYB102 genetically acts downstream of $A G L 16$}

(A-C) Seed germination of Col-0, agl16, myb102, and agl16 myb102 lines. Vernalized seeds were horizontally germinated on MS medium with or without $120 \mathrm{mM} \mathrm{NaCl}, 250 \mathrm{mM}$ mannitol, or $0.5 \mu \mathrm{M}$ ABA for 7 days before photographs were taken (A). Seed germination rate was counted at the indicated time points (B). Green cotyledon rate was counted at 7 days of germination $(\mathrm{C})$. Values are mean $\pm \mathrm{SD}(\mathrm{n}=3$ replicates, 60 seeds/replicate). Different letters indicate significant difference by one-way ANOVA $(\mathrm{P}<0.05)$.

(D-E) Primary root elongation of Col-0, agl16, myb102, and agll6 myb102 lines. Seeds were germinated on MS medium for 4 days respectively, and then seedlings were transferred to MS medium with or without $120 \mathrm{mM} \mathrm{NaCl}, 250 \mathrm{mM}$ mannitol, or $5 \mu \mathrm{M} \mathrm{ABA}$ and grown vertically for 7 days before photographs were taken (D) and primary root length was measured (E). Values are mean $\pm \mathrm{SD}$ ( $\mathrm{n}=3$ replicates, 30 seedlings/replicate). Different letters indicate significant difference by one-way ANOVA $(\mathrm{P}<0.05)$. 


\section{Parsed Citations}

Alvarez-Buylla, E.R., Garcia-Ponce, B., Sanchez, M.P., Espinosa-Soto, C., Garcia-Gomez, M.L., Pineyro-Nelson, A, and Garay-Arroyo, A (2019). MADS-box genes underground becoming mainstream: plant root developmental mechanisms. New Phytol.

Google Scholar: Author Only Title Only Author and Title

Alvarez-Buylla, E.R., Liljegren, S.J., Pelaz, S., Gold, S.E., Burgeff, C., Ditta, G.S., Vergara-Silva, F., and Yanofsky, M.F. (2000). MADS-box gene evolution beyond flowers: expression in pollen, endosperm, guard cells, roots and trichomes. Plant J 24, 457-466.

Google Scholar: Author Only Title Only Author and Title

An, D., Chen, J.G., Gao, Y.Q., Li, X., Chao, ZF., Chen, ZR., Li, Q.Q., Han, M.L., Wang, Y.L., Wang, Y.F., and Chao, D.Y. (2017). AtHKT1 drives adaptation of Arabidopsis thaliana to salinity by reducing floral sodium content. PLoS Genet 13, e1007086.

Google Scholar: Author Only Title Only Author and Title

Apse, M.P., Aharon, G.S., Snedden, W.A, and Blumwald, E. (1999). Salt tolerance conferred by overexpression of a vacuolar $\mathrm{Na}+/ \mathrm{H}+$ antiport in Arabidopsis. Science 285, 1256-1258.

Google Scholar: Author Only Title Only Author and Title

Bao, F., and Li, J.Y. (2002). Evidence That the Auxin Signaling Pathway Interacts with Plant Stress Response. Acta Botanica Sinica 44, 532-536.

Google Scholar: Author Only Title Only Author and Title

Barragan, V., Leidi, E.O., Andres, Z, Rubio, L., De Luca, A, Fernandez, J.A, Cubero, B., and Pardo, J.M. (2012). lon exchangers NHX1 and NHX2 mediate active potassium uptake into vacuoles to regulate cell turgor and stomatal function in Arabidopsis. The Plant cell 24, 1127-1142.

Google Scholar: Author Only Title Only Author and Title

Bartels, D., and Sunkar, R. (2005). Drought and salt tolerance in plants. Crit Rev Plant Sci 24, 23-58.

Google Scholar: Author Only Title Only Author and Title

Bassil, E., Tajima, H., Liang, Y.C., Ohto, M.A, Ushijima, K., Nakano, R., Esumi, T., Coku, A, Belmonte, M., and Blumwald, E. (2011). The Arabidopsis $\mathrm{Na}+/ \mathrm{H}+$ antiporters $\mathrm{NHX1}$ and $\mathrm{NHX} 2$ control vacuolar $\mathrm{pH}$ and $\mathrm{K}+$ homeostasis to regulate growth, flower development, and reproduction. The Plant cell 23, 3482-3497.

Google Scholar: Author Only Title Only Author and Title

Berthomieu, P., Conejero, G., Nublat, A, Brackenbury, W.J., Lambert, C., Savio, C., Uozumi, N., Oiki, S., Yamada, K., Cellier, F., Gosti, F., Simonneau, T., Essah, P.A, Tester, M., Very, AA, Sentenac, H., and Casse, F. (2003). Functional analysis of AtHKT1 in Arabidopsis shows that $\mathrm{Na}+$ recirculation by the phloem is crucial for salt tolerance. EMBO J 22, 2004-2014.

Google Scholar: Author Only Title Only Author and Title

Blumwald, E., Aharaon, G.S., and Apse, M.P. (2000). Sodium transport in plant cells. BBARev 1465, 140-151.

Google Scholar: Author Only Title Only Author and Title

Burgeff, C., Liljegren, S.J., Tapia-López, R., Yanofsky, M.F., and Avarez-Buylla, E.R. (2001). MADS-box gene expression in lateral primordia, meristems and differentiated tissues of Arabidopsis thaliana roots. Planta 214, 365-372.

Google Scholar: Author Only Title Only Author and Title

Cai, X.T., Xu, P., Zhao, P.X., Liu, R., Yu, L.H., and Xiang, C.B. (2014). Arabidopsis ERF109 mediates cross-talk between jasmonic acid and auxin biosynthesis during lateral root formation. Nat Commun 5, 5833.

Google Scholar: Author Only Title Only Author and Title

Callens, C., Tucker, M.R., Zhang, D., and Wilson, ZA (2018). Dissecting the role of MADS-box genes in monocot floral development and diversity. J Exp Bot 69, 2435-2459.

Google Scholar: Author Only Title Only Author and Title

Carles, C., Bies-Etheve, N.A, L., Leon-Kloosterziel, K.M., Koornneef, M.E., M. , and Delseny, M. (2002). Regulation of Arabidopsis thaliana Em genes: role of ABI5. Plant J 30, 373-383.

Google Scholar: Author Only Title Only Author and Title

Chan, $Z$ (2012). Expression profiling of ABA pathway transcripts indicates crosstalk between abiotic and biotic stress responses in Arabidopsis. Genomics 100, 110-115.

Google Scholar: Author Only Title Only Author and Title

Choi, W.G., Toyota, M., Kim, S.H., Hilleary, R., and Gilroy, S. (2014). Salt stress-induced Ca2+ waves are associated with rapid, longdistance root-to-shoot signaling in plants. Proc Natl Acad Sci U S A111, 6497-6502.

Google Scholar: Author Only Title Only Author and Title

Clough, S.J., and Bent, AF. (1998). Floral dip: a simplified method for Agrobacterium-mediated transformation of Arabidopsis thaliana.

Plant J 16, 735-743.

Google Scholar: Author Only Title Only Author and Title

Davenport, R.J., Munoz-Mayor, A, Jha, D., Essah, P.A, Rus, A, and Tester, M. (2007). The Na+ transporter AtHKT1;1 controls retrieval of $\mathrm{Na}+$ from the xylem in Arabidopsis. Plant Cell Environ 30, 497-507. 
Google Scholar: Author Only Title Only Author and Title

Deinlein, U., Stephan, AB., Horie, T., Luo, W., Xu, G., and Schroeder, J.I. (2014). Plant salt-tolerance mechanisms. Trends Plant Sci 19, 371-379.

Google Scholar: Author Only Title Only Author and Title

Denekamp, M., and Smeekens, S.C. (2003). Integration of wounding and osmotic stress signals determines the expression of the AtMYB102 transcription factor gene. Plant Physiol 132, 1415-1423.

Google Scholar: Author Only Title Only Author and Title

Ding, ZJ., Yan, J.Y., Li, G.X., Wu, ZC., Zhang, S.Q., and Zheng, S.J. (2014). WRKY41 controls Arabidopsis seed dormancy via direct regulation of $\mathrm{ABI} 3$ transcript levels not downstream of ABA Plant J 79, 810-823.

Google Scholar: Author Only Title Only Author and Title

Duan, L., Dietrich, D., Ng, C.H., Chan, P.M., Bhalerao, R., Bennett, M.J., and Dinneny, J.R. (2013). Endodermal ABA signaling promotes lateral root quiescence during salt stress in Arabidopsis seedlings. The Plant cell 25, 324-341.

Google Scholar: Author Only Title Only Author and Title

Dubos, C., Stracke, R., Grotewold, E., Weisshaar, B., Martin, C., and Lepiniec, L. (2010). MYB transcription factors in Arabidopsis. Trends Plant Sci 15, 573-581.

Google Scholar: Author Only Title Only Author and Title

Duszyn, M., Swiezawska, B., Szmidt-Jaworska, A, and Jaworski, K. (2019). Cyclic nucleotide gated channels (CNGCs) in plant signalling-Current knowledge and perspectives. J Plant Physiol 241, 153035.

Google Scholar: Author Only Title Only Author and Title

Finkelstein, R.R., and Lynch, T.J. (2000). The Arabidopsis abscisic acid response gene ABI5 encodes a basic leucine zipper transcription factor. The Plant cell 12, 599-609.

Google Scholar: Author Only Title Only Author and Title

Fujita, M., Fujita, Y., Noutoshi, Y., Takahashi, F., Narusaka, Y., Yamaguchi-Shinozaki, K., and Shinozaki, K. (2006). Crosstalk between abiotic and biotic stress responses: a current view from the points of convergence in the stress signaling networks. Curr Opin Plant Biol 9, 436-442.

Google Scholar: Author Only Title Only Author and Title

Fujita, Y., Fujita, M., Shinozaki, K., and Yamaguchi-Shinozaki, K. (2011). ABA-mediated transcriptional regulation in response to osmotic stress in plants. J Plant Res 124, 509-525.

Google Scholar: Author Only Title Only Author and Title

Gan, Y., Filleur, S., Rahman, A, Gotensparre, S., and Forde, B.G. (2005). Nutritional regulation of ANR1 and other root-expressed MADS-box genes in Arabidopsis thaliana. Planta 222, 730-742.

Google Scholar: Author Only Title Only Author and Title

Gan, Y., Bernreiter, A, Filleur, S., Abram, B., and Forde, B.G. (2012). Overexpressing the ANR1 MADS-box gene in transgenic plants provides new insights into its role in the nitrate regulation of root development. Plant Cell Physiol 53, $1003-1016$.

Google Scholar: Author Only Title Only Author and Title

Garay-Arroyo, A, Ortiz-Moreno, E., de la Paz Sanchez, M., Murphy, AS., Garcia-Ponce, B., Marsch-Martinez, N., de Folter, S., CorveraPoire, A, Jaimes-Miranda, F., Pacheco-Escobedo, M.A, Dubrovsky, J.G., Pelaz, S., and Avarez-Buylla, E.R. (2013). The MADS transcription factor XAL2/AGL14 modulates auxin transport during Arabidopsis root development by regulating PIN expression. EMBO J 32, 2884-2895.

Google Scholar: Author Only Title Only Author and Title

Garcia-Cruz, K.V., Garcia-Ponce, B., Garay-Arroyo, A, Sanchez, M.P., Ugartechea-Chirino, Y., Desvoyes, B., Pacheco-Escobedo, M.A, Tapia-Lopez, R., Ransom-Rodriguez, I., Gutierrez, C., and Alvarez-Buylla, E.R. (2016). The MADS-box XAANTAL1 increases proliferation at the Arabidopsis root stem-cell niche and participates in transition to differentiation by regulating cell-cycle components. Ann Bot 118, 787-796.

Google Scholar: Author Only Title Only Author and Title

Geng, Y., Wu, R., Wee, C.W., Xie, F., Wei, X., Chan, P.M.Y., Tham, C., Duan, L., and Dinneny, J.R. (2013). Aspatio-temporal understanding of growth regulation during the salt stress response in Arabidopsis. The Plant cell 25, $2132-2154$.

Google Scholar: Author Only Title Only Author and Title

Giraudat, J., Hauge, B.M., Valon, C., Smalle, J., Parcy, F., and Goodman, H.M. (1992). Isolation of the Arabidopsis ABI3 gene by positional cloning. The Plant cell 4.

Google Scholar: Author Only Title Only Author and Title

Golldack, D., Luking, I., and Yang, O. (2011). Plant tolerance to drought and salinity: stress regulating transcription factors and their functional significance in the cellular transcriptional network. Plant cell reports 30, 1383-1391.

Google Scholar: Author Only Title Only Author and Title

Golldack, D., Li, C., Mohan, H., and Probst, N. (2014). Tolerance to drought and salt stress in plants: Unraveling the signaling networks. Front Plant Sci 5, 151. 
Hellens, R.P., Alan, AC., Friel, E.N., Bolitho, K., Grafton, K., Templeton, M.D., Karunairetnam, S., Gleave, AP., and Laing, W.A (2005). Transient expression vectors for functional genomics, quantification of promoter activity and RNA silencing in plants. Plant Methods 1 , 13.

Google Scholar: Author Only Title Only Author and Title

Horie, T., Hauser, F., and Schroeder, J.I. (2009). HKT transporter-mediated salinity resistance mechanisms in Arabidopsis and monocot crop plants. Trends Plant Sci 14, 660-668.

Google Scholar: Author Only Title Only Author and Title

Horie, T., Sugawara, M., Okunou, K., Nakayama, H., Schroeder, J.I., Shinmyo, A, and Yoshida, K. (2008). Functions of HKT transporters in sodium transport in roots and in protecting leaves from salinity stress. Plant Biotech 25, 233-239.

Google Scholar: Author Only Title Only Author and Title

Hwang, S.M., Kim, D.W., Woo, M.S., Jeong, H.S., Son, Y.S., Akhter, S., Choi, G.J., and Bahk, J.D. (2014). Functional characterization of Arabidopsis HsfA6a as a heat-shock transcription factor under high salinity and dehydration conditions. Plant Cell Environ 37, 12021222.

Google Scholar: Author Only Title Only Author and Title

Jefferson, R.A, Kavanagh, T.A, and Bevan, M.W. (1987). GUS fusions: beta-glucuronidase as a sensitive and versatile gene fusion marker in higher plants. EMBO J 6, 3901-3907.

Google Scholar: Author Only Title Only Author and Title

Jiang, W., and Yu, D. (2009). Arabidopsis WRKY2 transcription factor mediates seed germination and postgermination arrest of development by abscisic acid. BMC Plant Biol 9, 96.

Google Scholar: Author Only Title Only Author and Title

Jiang, Z, Zhou, X., Tao, M., Yuan, F., Liu, L., Wu, F., Wu, X., Xiang, Y., Niu, Y., Liu, F., Li, C., Ye, R., Byeon, B., Xue, Y., Zhao, H., Wang, H.N., Crawford, B.M., Johnson, D.M., Hu, C., Pei, C., Zhou, W., Swift, G.B., Zhang, H., Vo-Dinh, T., Hu, Z, Siedow, J.N., and Pei, ZM. (2019). Plant cell-surface GIPC sphingolipids sense salt to trigger $\mathrm{Ca}(2+)$ influx. Nature 572, 341-346.

Google Scholar: Author Only Title Only Author and Title

Knight, H., Trewavas, AJ., and Knight, M.R. (1997). Calcium signaling in Arabidopsis thaliana responding to drought and salinity. Plant J 12, 1067-1078.

Google Scholar: Author Only Title Only Author and Title

Ku, Y.S., Sintaha, M., Cheung, M.Y., and Lam, H.M. (2018). Plant hormone signaling crosstalks between biotic and abiotic stress responses. Int J Mol Sci 19.

Google Scholar: Author Only Title Only Author and Title

Kurusu, T., Kuchitsu, K., Nakano, M., Nakayama, Y., and lida, H. (2013). Plant mechanosensing and Ca2+ transport. Trends Plant Sci 18, 227-233.

Google Scholar: Author Only Title Only Author and Title

Lee, J., and Lee, I. (2010). Regulation and function of SOC1, a flowering pathway integrator. J Exp Bot 61, 2247-2254.

Google Scholar: Author Only Title Only Author and Title

Lei, ZY., Zhao, P., Cao, M.J., Cui, R., Chen, X., Xiong, L.Z, Zhang, Q.F., Oliver, D.J., and Xiang, C.B. (2007). High-throughput binary vectors for plant gene function analysis. J Integr Plant Biol 49, 556-567.

Google Scholar: Author Only Title Only Author and Title

Leidi, E.O., Barragán, V., Rubio, L., El-Hamdaoui, A, Ruiz, M.T., Cubero, B., Fernández, J.A, Bressan, R.A, Hasegawa, P.M., Quintero, F.J., and Pardo, J.M. (2010). The AtNHX1 exchanger mediates potassium compartmentation in vacuoles of transgenic tomato. Plant $J$ 61, 495-506.

Google Scholar: Author Only Title Only Author and Title

Lin, J.H., Yu, L.H., and Xiang, C.B. (2019). ARABIDOPSIS NITRATE REGULATED 1 acts as a negative modulator of seed germination by activating ABI3 expression. New Phytol 225, 835-847.

Google Scholar: Author Only Title Only Author and Title

Lopez-Molina, L., Mongrand, S., McLachlin, D.T.C., B. T. , and Chua, N.H. (2002). ABI5 acts downstream of ABI3 to execute an ABA dependent growth arrest during germination. Plant J 32, 317-328.

Google Scholar: Author Only Title Only Author and Title

Ma, L., Zhang, H., Sun, L., Jiao, Y., Zhang, G., Miao, C., and Hao, F. (2011). NADPH oxidase AtrbohD and AtrbohF function in ROSdependent regulation of $\mathrm{Na}+/ \mathrm{K}+$ homeostasis in Arabidopsis under salt stress. J Exp Bot 63, 305-317.

Google Scholar: Author Only Title Only Author and Title

Maathuis, F.J. (2014). Sodium in plants: perception, signalling, and regulation of sodium fluxes. J Exp Bot 65, 849-858.

Google Scholar: Author Only Title Only Author and Title

Manishankar, P., Wang, N., Koster, P., Alatar, AA, and Kudla, J. (2018). Calcium signaling during salt stress and in the regulation of ion homeostasis. J Exp Bot 69. 
Mao, J.L., Miao, ZQ., Wang, Z, Yu, L.H., Cai, X.T., and Xiang, C.B. (2016). Arabidopsis ERF1 mediates cross-talk between ethylene and auxin biosynthesis during primary root elongation by regulating ASA1 Expression. PLoS Genetics 12, e1005760.

Google Scholar: Author Only Title Only Author and Title

Maser, P., Eckelman, B., Vaidyanathan, R., Horie, T., and Fairbairn, D.J. (2002). Altered shoot/root Na+ distribution and bifurcating salt sensitivity in Arabidopsis by genetic disruption of the Na+ transporter AtHKT1. FEBS Lett 531.

Google Scholar: Author Only Title Only Author and Title

Messenguy, F., and Dubois, E. (2003). Role of MADS box proteins and their cofactors in combinatorial control of gene expression and cell development. Gene 316, 1-21.

Google Scholar: Author Only Title Only Author and Title

Miao, ZQ., Zhao, P.X., Mao, J.L., Yu, L.H., Yuan, Y., Tang, H., Liu, ZB., and Xiang, C.B. (2018). HOMEOBOX PROTEIN52 mediates the crosstalk between ethylene and auxin signaling during primary root elongation by modulating auxin transport-related gene expression. The Plant cell 30, 2761-2778.

Google Scholar: Author Only Title Only Author and Title

Miller, G., Suzuki, N., Ciftci-Yilmaz, S., and Mittler, R. (2010). Reactive oxygen species homeostasis and signalling during drought and salinity stresses. Plant Cell Environ 33, 453-467.

Google Scholar: Author Only Title Only Author and Title

Moller, I.S., Gilliham, M., Jha, D., Mayo, G.M., Roy, S.J., Coates, J.C., Haseloff, J., and Tester, M. (2009). Shoot Na+ exclusion and increased salinity tolerance engineered by cell type-specific alteration of $\mathrm{Na}+$ transport in Arabidopsis. The Plant cell 21, 2163-2178.

Google Scholar: Author Only Title Only Author and Title

Mu, R.L., Cao, Y.R., Liu, Y.F., Lei, G., Zou, H.F., Liao, Y., Wang, H.W., Zhang, W.K., Ma, B., Du, J.Z, Yuan, M., Zhang, J.S., and Chen, S.Y. (2009). An R2R3-type transcription factor gene AtMYB59 regulates root growth and cell cycle progression in Arabidopsis. Cell Res 19, 1291-1304.

Google Scholar: Author Only Title Only Author and Title

Mukhopadhyay, A, Deplancke, B., Walhout, AJ., and Tissenbaum, H.A (2008). Chromatin immunoprecipitation (ChIP) coupled to detection by quantitative real-time PCR to study transcription factor binding to DNA in Caenorhabditis elegans. Nat Protoc 3, $698-709$.

Google Scholar: Author Only Title Only Author and Title

Munns, R., and Gilliham, M. (2015). Salinity tolerance of crops - what is the cost? New Phytol 208, 668-673.

Google Scholar: Author Only Title Only Author and Title

Nakagawa, T., Kurose, T., Hino, T., Tanaka, K., Kawamukai, M., Niwa, Y., Toyooka, K., Matsuoka, K., Jinbo, T., and Kimura, T. (2007). Development of series of gateway binary vectors, pGWBs, for realizing efficient construction of fusion genes for plant transformation. J Biosci Bioeng 104, 34-41.

Google Scholar: Author Only Title Only Author and Title

Nakashima, K., Shinwari, Z, K. , Sakuma, Y., Seki, M., Miura, S., Shinozaki, K., and Yamaguchi-Shinozaki, K. (2000). Organization and expression of two Arabidopsis DREB2 genes encoding DRE-binding proteins involved in dehydration- and high-salinity-responsive gene expression. Plant Mol Bio 42, 657-665.

Google Scholar: Author Only Title Only Author and Title

Pandey, G.K., Grant, J.J., Cheong, Y.H., Kim, B.G., Li, L., and Luan, S. (2005). ABR1, an APETALA2-domain transcription factor that functions as a repressor of ABA response in Arabidopsis. Plant Physiol 139, 1185-1193.

Google Scholar: Author Only Title Only Author and Title

Pardo, J.M., Cubero, B., Leidi, E.O., and Quintero, F.J. (2006). Akali cation exchangers: roles in cellular homeostasis and stress tolerance. J Exp Bot 57, 1181-1199.

Google Scholar: Author Only Title Only Author and Title

Pinyopich, A, Ditta, G.S., Savidge, B., Liljegren, S.J., Baumann, E., Wisman, E., and Yanofsky, M.F. (2003). Assessing the redundancy of MADS-box genes during carpel and ovule development. Nature 424, 85-88.

Google Scholar: Author Only Title Only Author and Title

Piskurewicz, U., Jikumaru, Y., Kinoshita, N., Nambara, E., Kamiya, Y., and Lopez-Molina, L. (2008). The gibberellic acid signaling repressor RGL2 inhibits Arabidopsis seed germination by stimulating abscisic acid synthesis and ABI5 activity. The Plant cell 20, 27292745.

Google Scholar: Author Only Title Only Author and Title

Qiu, Q.S., Guo, Y., Dietrich, M.A, Schumaker, K.S., and Zhu, J.K. (2002). Regulation of SOS1, a plasma membrane Na+/H+ exchanger in Arabidopsis thaliana, by SOS2 and SOS3. P NATL ACAD SCI USA99, 8436-8441.

Google Scholar: Author Only Title Only Author and Title

Ren, ZH., Gao, J.P., Li, L.G., Cai, X.L., Huang, W., Chao, D.Y., Zhu, M.Z, Wang, ZY., Luan, S., and Lin, H.X. (2005). A rice quantitative trait locus for salt tolerance encodes a sodium transporter. Nat Genet 37, 1141-1146.

Google Scholar: Author Only Title Only Author and Title 
Rounsley, S.D., Ditta, G.S., and Yanofsky, M.F. (1995). Diverse Roles for MADS Box Genes in Arabidopsis Development. Plant Cell 7, 1259-1269.

Google Scholar: Author Only Title Only Author and Title

Roy, S. (2016). Function of MYB domain transcription factors in abiotic stress and epigenetic control of stress response in plant genome. Plant Signal Behav 11, e1117723.

Google Scholar: Author Only Title Only Author and Title

Schroeder, J.I., Delhaize, E., Frommer, W.B., Guerinot, M.L., Harrison, M.J., Herrera-Estrella, L., Horie, T., Kochian, L.V., Munns, R., Nishizawa, N.K., Tsay, Y.F., and Sanders, D. (2013). Using membrane transporters to improve crops for sustainable food production. Nature 497, 60-66.

Google Scholar: Author Only Title Only Author and Title

Shabala, S., Wu, H., and Bose, J. (2015). Salt stress sensing and early signalling events in plant roots: Current knowledge and hypothesis. Plant Sci 241, 109-119.

Google Scholar: Author Only Title Only Author and Title

Shkolnik-Inbar, D., Adler, G., and Bar-Zvi, D. (2013). ABI4 downregulates expression of the sodium transporter HKT1;1 in Arabidopsis roots and affects salt tolerance. Plant $\mathrm{J}$ 73, 993-1005.

Google Scholar: Author Only Title Only Author and Title

Sun, F., Zhang, W., Hu, H., Li, B., Wang, Y., Zhao, Y., Li, K., Liu, M., and Li, X. (2008). Salt modulates gravity signaling pathway to regulate growth direction of primary roots in Arabidopsis. Plant Physiol 146, 178-188.

Google Scholar: Author Only Title Only Author and Title

Sunarpi, Horie, T., Motoda, J., Kubo, M., Yang, H., Yoda, K., Horie, R., Chan, W.Y., Leung, H.Y., Hattori, K., Konomi, M., Osumi, M., Yamagami, M., Schroeder, J.I., and Uozumi, N. (2005). Enhanced salt tolerance mediated by AtHKT1 transporter-induced Na+ unloading from xylem vessels to xylem parenchyma cells. Plant $\mathrm{J} 44,928-938$.

Google Scholar: Author Only Title Only Author and Title

Swarup, R., Perry, P., Hagenbeek, D., Van Der Straeten, D., Beemster, G.T., Sandberg, G., Bhalerao, R., Ljung, K., and Bennett, M.J. (2007). Ethylene upregulates auxin biosynthesis in Arabidopsis seedlings to enhance inhibition of root cell elongation. Plant Cell 19, 2186-2196.

Google Scholar: Author Only Title Only Author and Title

Tapia-Lopez, R., Garcia-Ponce, B., Dubrovsky, J.G., Garay-Arroyo, A, Perez-Ruiz, R.V., Kim, S.H., Acevedo, F., Pelaz, S., and AvarezBuylla, E.R. (2008). An AGAMOUS-related MADS-box gene, XAL1 (AGL12), regulates root meristem cell proliferation and flowering transition in Arabidopsis. Plant Physiol 146, 1182-1192.

Google Scholar: Author Only Title Only Author and Title

Urao, T., Yakubov, B., Satoh, R., Yamaguchi-Shinozaki, K., Seki, M., Hirayama, T., and Shinozaki, K. (1999). Atransmembrane hybridtype-histidine kinase in arabidopsis functions as an osmosensor. The Plant cell 11, 1743-1754.

Google Scholar: Author Only Title Only Author and Title

Vishal, B., and Kumar, P.P. (2018). Regulation of seed germination and abiotic stresses by gibberellins and abscisic Aacid. Front Plant Sci 9, 838.

Google Scholar: Author Only Title Only Author and Title

Wang, H., Pan, J., Li, Y., Lou, D., Hu, Y., and Yu, D. (2016). The DELLA-CONSTANS transcription factor cascade integrates gibberellic acid and photoperiod signaling to regulate flowering. Plant Physiol 172, 479-488.

Google Scholar: Author Only Title Only Author and Title

Wu, H. (2018). Plant salt tolerance and $\mathrm{Na}+$ sensing and transport. Crop J 6, 215-225.

Google Scholar: Author Only Title Only Author and Title

Xie, Z, Nolan, T.M., Jiang, H., and Yin, Y. (2019). AP2/ERF transcription factor regulatory networks in hormone and abiotic stress responses in Arabidopsis. Front Plant Sci 10, 228.

Google Scholar: Author Only Title Only Author and Title

Yamaguchi-Shinozaki, K., and Shinozaki, K. (2006). Transcriptional regulatory networks in cellular responses and tolerance to dehydration and cold stresses. Annu Rev Plant Biol 57, 781-803.

Google Scholar: Author Only Title Only Author and Title

Yang, O., Popova, O.V., Suthoff, U., Luking, I., Dietz, K.J., and Golldack, D. (2009). The Arabidopsis basic leucine zipper transcription factor AtbZP24 regulates complex transcriptional networks involved in abiotic stress resistance. Gene 436, 45-55.

Google Scholar: Author Only Title Only Author and Title

Yang, Y., and Guo, Y. (2018). Elucidating the molecular mechanisms mediating plant salt-stress responses. New Phytol 217, $523-539$. Google Scholar: Author Only Title Only Author and Title

Yokoi, S., Quintero, F.J., Cubero, B., Ruiz, M.T., Bressan, R.A, Hasegawa, P.M., and Pardo, J.M. (2002). Differential expression and function of Arabidopsis thaliana $\mathrm{NHX} \mathrm{Na+/H+} \mathrm{antiporters} \mathrm{in} \mathrm{the} \mathrm{salt} \mathrm{stress} \mathrm{response.} \mathrm{Plant} \mathrm{J} 30$.

Google Scholar: Author Only Title Only Author and Title 
Yoo, S.D., Cho, Y.H., and Sheen, J. (2007). Arabidopsis mesophyll protoplasts: a versatile cell system for transient gene expression analysis. Nat Protoc 2, 1565-1572.

Google Scholar: Author Only Title Only Author and Title

Yu, C., Su, S., Xu, Y., Zhao, Y., Yan, A, Huang, L., Ali, I., and Gan, Y. (2014a). The effects of fluctuations in the nutrient supply on the expression of five members of the AGL17 clade of MADS-box genes in rice. PLoS One 9, e105597.

Google Scholar: Author Only Title Only Author and Title

Yu, L.H., Miao, ZQ., Qi, G.F., Wu, J., Cai, X.T., Mao, J.L., and Xiang, C.B. (2014b). MADS-box transcription factor AGL21 regulates lateral root development and responds to multiple external and physiological signals. Mol Plant 7, 1653-1669.

Google Scholar: Author Only Title Only Author and Title

Yu, L.H., Wu, J., Zhang, ZS., Miao, ZQ., Zhao, P.X., Wang, Z, and Xiang, C.B. (2017). Arabidopsis MADS-Box transcription factor AGL21 acts as environmental surveillance of seed germination by regulating ABI5 expression. Mol Plant 10, 834-845.

Google Scholar: Author Only Title Only Author and Title

Yuan, F., Yang, H., Xue, Y., Kong, D., Ye, R., Li, C., Zhang, J., Theprungsirikul, L., Shrift, T., Krichilsky, B., Johnson, D.M., Swift, G.B., He, Y., Siedow, J.N., and Pei, ZM. (2014). OSCA1 mediates osmotic-stress-evoked Ca2+ increases vital for osmosensing in

Arabidopsis. Nature 514, 367-371.

Google Scholar: Author Only Title Only Author and Title

Zhang, H.M., and Forde, B.G. (1998). An Arabidopsis MADS Box Gene That Controls Nutrient-Induced Changes in Root Architecture.

Science 279, 407-409.

Google Scholar: Author Only Title Only Author and Title

Zhao, P.-X., Miao, Z-Q., Zhang, J., Chen, S.-Y., Liu, Q.-Q., and Xiang, C.-B. (2020). Arabidopsis MADS-box factor AGL16 negatively regulates drought resistance via stomatal density and stomatal movement. J Exp Bot.

Google Scholar: Author Only Title Only Author and Title

Zhu, J.K. (2002). Salt and drought stress signal transduction in plants. Annu Rev Plant Biol 53, 247-273.

Google Scholar: Author Only Title Only Author and Title

Zhu, J.K. (2003). Regulation of ion homeostasis under salt stress. Curr Opin Plant Biol 6, 441-445.

Google Scholar: Author Only Title Only Author and Title

Zhu, J.K. (2016). Abiotic stress signaling and responses in plants. Cell 167, 313-324.

Google Scholar: Author Only Title Only Author and Title

Zhu, L., Guo, J., Ma, Z, Wang, J., and Zhou, C. (2018). Arabidopsis transcription factor MYB102 increases plant susceptibility to aphids by substantial activation of ethylene biosynthesis. Biomole 8.

Google Scholar: Author Only Title Only Author and Title 